\title{
Who Should Buy Long-Term Bonds?
}

\section{Citation}

Campbell, John Y., and Luis M. Viceira. 2001. Who should buy long-term bonds? American Economic Review 91, no. 1: 99-127.

\section{Published Version}

http://dx.doi.org/10.1093/0198296940.003.0003

\section{Permanent link}

http://nrs.harvard.edu/urn-3:HUL.InstRepos:3128709

\section{Terms of Use}

This article was downloaded from Harvard University's DASH repository, and is made available under the terms and conditions applicable to Other Posted Material, as set forth at http:// nrs.harvard.edu/urn-3:HUL.InstRepos:dash.current.terms-of-use\#LAA

\section{Share Your Story}

The Harvard community has made this article openly available.

Please share how this access benefits you. Submit a story.

\section{Accessibility}



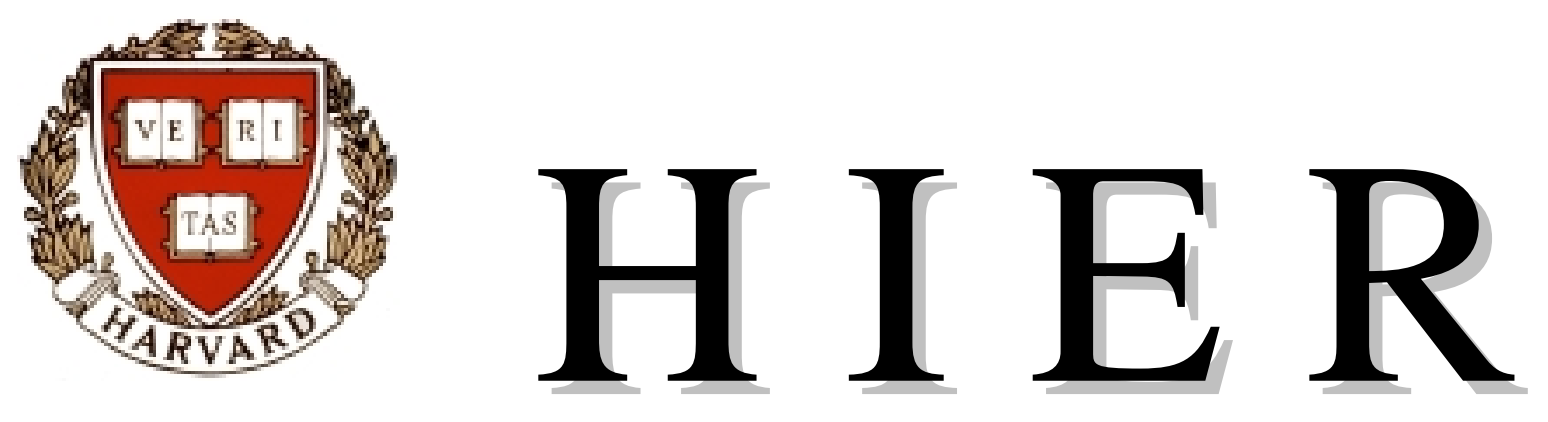

\title{
Harvard Institute of Economic Research
}

Discussion Paper Number 1895

\section{Who Should Buy Long-Term Bonds?}

By

\section{John Y. Campbell and Luis M. Viceira}

\author{
December 1999 \\ Harvard University \\ Cambridge, Massachusetts
}

This paper can be downloaded without charge from the Social Science Research Network electronic library at: http://papers.ssrn.com/paper.taf?abstract_id=140271

or

http://post.economics.harvard.edu/hier/2000papers/2000list.html 


\title{
Who Should Buy Long-Term Bonds?
}

\author{
John Y. Campbell and Luis M. Viceira ${ }^{1}$
}

First draft: October 1997

This version: December 1999

\footnotetext{
${ }^{1}$ Campbell: Department of Economics, Littauer Center 213, Harvard University, Cambridge MA 02138, USA, and NBER. Tel 617-496-6448, email john_campbell@harvard.edu. Viceira: Harvard Business School, Morgan Hall 367, Boston MA 02163. Tel 617-495-6331, email lviceira@hbs.edu. Campbell acknowledges the financial support of the National Science Foundation and Viceira acknowledges the financial support of the Bank of Spain. We are grateful for helpful comments on earlier drafts by Andrew Abel, Qiang Dai, Sanjiv Das, Ravi Jagannathan, Stephen Schaefer, Costis Skiadas, and seminar participants at Chicago, Columbia, Duke, FAME, MIT, Northwestern, Wharton, the NBER Summer Institute, the WFA meetings, and the CEPR European Summer Symposium in Financial Markets at Studienzentrum Gerzensee.
} 


\begin{abstract}
According to conventional wisdom, long-term bonds are appropriate for conservative long-term investors. This paper develops a model of optimal consumption and portfolio choice for infinite-lived investors with recursive utility who face stochastic interest rates, solves the model using an approximate analytical method, and evaluates the conventional wisdom. As risk aversion increases, the myopic component of risky asset demand disappears but the intertemporal hedging component does not. Conservative investors hold assets to hedge the risk that real interest rates will decline. Long-term inflation-indexed bonds are most suitable for this purpose, but nominal bonds may also be used if inflation risk is low.
\end{abstract}

JEL classification: G12. 


\title{
Who Should Buy Long-Term Bonds?
}

\author{
John Y. Campbell and Luis M. Viceira*
}

According to conventional wisdom, long-term bonds are appropriate for conservative longterm investors. This paper develops a model of optimal consumption and portfolio choice for infinite-lived investors with recursive utility who face stochastic interest rates, solves the model using an approximate analytical method, and evaluates the conventional wisdom. As risk aversion increases, the myopic component of risky asset demand disappears but the intertemporal hedging component does not. Conservative investors hold assets to hedge the risk that real interest rates will decline. Long-term inflation-indexed bonds are most suitable for this purpose, but nominal bonds may also be used if inflation risk is low. (JEL G12)

Long-term bonds have been issued for centuries, and they remain extremely common financial instruments. It is natural to suppose that bonds have been popular because they meet the needs of an investor clientele. Investment advisers and financial journalists, for example, often say that bonds are appropriate for long-term investors who seek a stable income.

Curiously, modern financial economics has had little to say about the demand for longterm bonds. In the early postwar period John Hicks (1946), following John M. Keynes (1930) 
and Frederick Lutz (1940), argued that investors would naturally prefer to hold short-term bonds and would only hold long-term bonds if compensated by a term premium. Franco Modigliani and Richard Sutch (1966) countered that some investors might have a preference for long-term bonds (a long-term "preferred habitat"), and such investors would require a premium to go short, not a premium to go long. However Modigliani and Sutch were vague about the characteristics of investors that would lead to a long-term preferred habitat. They took it as a given that some investors would desire stable wealth at a long rather than a short horizon. ${ }^{1}$

Since the 1960's there has been a vast increase in the sophistication of bond pricing models, but little further progress has been made in understanding the demand for longterm bonds. Recent authors, building on the seminal contributions of Oldrich Vasicek (1977) and John Cox et al. (1985), have related term premia to the covariances of bond returns with an exogenously specified stochastic discount factor, but have not asked what bond portfolios are optimal for different types of investors. ${ }^{2}$

One reason for this gap in the literature may be that it is extremely hard to characterize optimal portfolio strategies for long-term investors. Paul A. Samuelson (1969) and Robert C. Merton $(1969,1971)$ obtained some explicit results under the assumption that real asset returns are independently and identically distributed over time; but this assumption implies that real interest rates are constant, so in the absence of inflation uncertainty - or with full indexation of bond payments to inflation - bond returns are nonrandom and all bonds are 
perfect substitutes for cash. Stanley Fischer (1975), Zvi Bodie et al. (1985), and Alan Viard (1993) have nonetheless used this assumption to study bond demand. In Fischer's model there is one nominal bond with a fixed nominal interest rate, and one inflation-indexed bond with a fixed real interest rate. The maturity of these bonds need not be specified, since bonds of all maturities are perfect substitutes for each other. ${ }^{3}$ Bodie et al. use historical data to estimate the variance-covariance matrix of real returns on nominal bonds, assuming that this matrix and mean real bond returns are constant over time. In their model random inflation allows imperfect substitutability among nominal bonds of different maturities, but constant real interest rates imply that long-term and short-term indexed bonds are perfect substitutes. Viard uses the same framework as Bodie et al. and derives some further analytical results.

Merton $(1969,1971,1973)$ studied the intertemporal portfolio choice problem with timevarying investment opportunities, introducing the important concept of intertemporal hedging demand for financial assets, but he did not obtain explicit solutions for portfolio weights. Recently a number of authors such as Pierluigi Balduzzi and Anthony Lynch (1999), Nicholas C. Barberis (1999), Michael Brandt (1999), and Michael Brennan et al. (1997) have used numerical methods to solve particular long-run portfolio choice problems, while Tong Suk Kim and Edward Omberg (1996) and John Y. Campbell and Luis M. Viceira (1999) have derived some analytical results, but these papers generally concentrate on the choice between cash and equities rather than the demand for long-term bonds. ${ }^{4}$

A shared assumption of this research is that investors live exclusively off financial wealth 
and do not have any labor income. Bodie et al. (1991) show that if labor income is riskless, or if shocks to labor income can be perfectly hedged with risky assets, then labor income can be treated as an implicit holding of financial assets. In this case the results of the literature apply to the total of explicit and implicit asset holdings. When labor income has unhedgeable risk, things become more complicated and numerical or approximate analytical solution methods are required (John Heaton and Deborah Lucas 1996, Joao Cocco et al. 1998, Viceira 1999).

In this paper we study intertemporal portfolio choice in an environment with random real interest rates. For simplicity we assume that investors have only financial wealth and no labor income. We use an approximation technique developed in our earlier papers (Campbell 1993, Campbell and Viceira 1999) to replace the intractable portfolio choice problem with an approximate problem that can be solved using the method of undetermined coefficients. We use the approximate solution to understand the demand for long-term bonds.

We calibrate our model to historical data on the US term structure of interest rates, and report optimal portfolios for investors with a wide range of different attitudes towards risk. In order to study the effects of inflation risk on optimal bond portfolios and investor utility, we compare the solutions to our model when only indexed bonds are available with the solutions when only nominal, or both nominal and indexed bonds are available. We also allow for borrowing and short-sales constraints, and for the possibility of investment in equities. 
We begin by specifying a simple two-factor model of the term structure of interest rates, augmented to fit equity as well as bond returns. The two factors are the log real interest rate and the log expected rate of inflation. Each factor follows a normal first-order autoregressive $(\mathrm{AR}(1))$ process with constant variance. This implies that log bond yields are linear in the factors and the model is in the tractable "affine yield" class (Dai and Singleton 1999, Darrell Duffie and Rui Kan 1996). The model for the real term structure is a discrete-time version of Vasicek (1977), while the model for the nominal term structure is a discrete-time version of Terence Langetieg (1980). Closely related models are discussed in Campbell et al. (1997), Chapter $11 .{ }^{5}$

Next we consider the portfolio choice problem for an infinite-lived investor who has only financial wealth and must choose consumption and optimal portfolio weights in each period. Because the investor is infinite-lived, she does not value stability of wealth at any unique horizon; rather she cares about the long-run properties of her consumption path. We assume that the investor's preferences are of the form suggested by Lawrence Epstein and Stanley Zin $(1989,1991)$ and Philippe Weil (1989); the investor has constant relative risk aversion and constant intertemporal elasticity of substitution in consumption, but these parameters need not be related to one another. Epstein-Zin preferences nest the traditional power-utility specification in which relative risk aversion is the reciprocal of the intertemporal elasticity of substitution.

We show that the investor's demand for long-term bonds can be decomposed into a 
"myopic" demand and a "hedging" demand. Myopic demand depends positively on the term premium, and inversely on the variance of long-term bond returns and the investor's risk aversion. As risk aversion increases, myopic demand shrinks to zero. Hedging demand, on the other hand, is proportional to one minus the reciprocal of risk aversion. It is zero when risk aversion is one but accounts for all bond demand when risk aversion is infinitely large. We show that an infinitely risk-averse investor with zero intertemporal elasticity of substitution in consumption will choose an indexed bond portfolio that is equivalent to an indexed perpetuity, that is, a portfolio that delivers a riskless stream of real consumption. In this way we are able to support the commonsense view that long-term bonds are appropriate for long-lived investors who desire stability of income.

Our analysis delivers explicit solutions for portfolio weights, consumption rules, and investor welfare. We can compare investor behavior under alternative assumptions about the available menu of assets. We find that when indexed bonds are not available, investors facing a given interest-rate process shorten their bond portfolios and increase their precautionary savings. This has serious utility costs for conservative investors, who are much better off when they have the opportunity to buy indexed bonds. In general equilibrium, of course, such changes in asset demands are likely to alter the interest-rate process itself, but we do not explore this effect.

We also consider optimal portfolios when equities, as well as bonds, are available. We find that the ratio of bonds to equities in the optimal portfolio increases with the coefficient of 
relative risk aversion. As Niko Canner et al. (1997) have pointed out, this is consistent with conventional portfolio advice but inconsistent with static mean-variance analysis. The static mean-variance model with a riskless one-period asset ("cash") predicts that all investors should hold a single mutual fund of risky assets; more conservative investors should increase the ratio of cash to the risky mutual fund, but should not change their relative holdings of risky assets. Our model helps to resolve the asset allocation puzzle identified by Canner et al.; more generally it underscores the dangers of using static portfolio choice theory to study the dynamic problems faced by long-term investors.

The organization of the paper is as follows. Section I presents the two-factor term structure model, and shows how it can be solved for bond prices at all maturities. Section II sets up the investor's intertemporal consumption and portfolio choice problem, explains our approximation to the problem, and discusses the approximate solution in the case where only indexed bonds are available. Section III asks how things change when only nominal bonds, or both nominal and indexed bonds, are available. This section also considers the consumption and portfolio choice problem in the presence of equities, and shows how to impose borrowing and short-sales constraints. Section IV concludes. 


\section{A Two-Factor Model of the Term Structure of Nominal Interest Rates}

\section{A. Specification of the model}

Our focus in this paper is the microeconomic problem of portfolio choice for a longterm investor facing exogenous bond returns. In order to generate empirically reasonable and theoretically well-specified bond returns, however, we start by writing down a general equilibrium bond pricing model. We consider a discrete-time, two-factor homoskedastic model that allows for non-zero correlation between innovations in the short-term real interest rate and innovations in expected inflation.

This two-factor, homoskedastic model is the simplest model of the term structure of interest rates that allows us to distinguish between inflation-indexed and nominal bonds. It would be possible to consider more factors and to allow for conditional heteroskedasticityfor example, using square-root factor processes. However, while we could fit the data better in this way, we would add mathematical complexity without gaining substantial economic insights into the long-run portfolio choice problem.

The real part of the model is determined by the stochastic discount factor (SDF) $M_{t+1}$ that prices all assets in the economy. In a representative-agent framework the SDF can be related to the marginal utility of a representative investor, but here we simply use it as a device to generate a complete set of bond prices. We assume that $M_{t+1}$ has the following 
lognormal structure, a discrete-time version of Vasicek (1977):

$$
\begin{aligned}
-m_{t+1} & =x_{t}+v_{m, t+1}, \\
x_{t+1} & =\left(1-\phi_{x}\right) \mu_{x}+\phi_{x} x_{t}+\varepsilon_{x, t+1}, \\
v_{m, t+1} & =\beta_{m x} \varepsilon_{x, t+1}+\varepsilon_{m, t+1},
\end{aligned}
$$

where $m_{t+1}=\log \left(M_{t+1}\right)$ and $x_{t}$, the one-period-ahead conditional expectation of $m_{t+1}$, follows an $\mathrm{AR}(1)$ process.

The nominal part of the model is also characterized by a lognormal, conditionally homoskedastic structure:

$$
\begin{aligned}
\pi_{t+1} & =z_{t}+v_{\pi, t+1}, \\
z_{t+1} & =\left(1-\phi_{z}\right) \mu_{z}+\phi_{z} z_{t}+v_{z, t+1}, \\
v_{z, t+1} & =\beta_{z x} \varepsilon_{x, t+1}+\beta_{z m} \varepsilon_{m, t+1}+\varepsilon_{z, t+1}, \\
v_{\pi, t+1} & =\beta_{\pi x} \varepsilon_{x, t+1}+\beta_{\pi m} \varepsilon_{m, t+1}+\beta_{\pi z} \varepsilon_{z, t+1}+\varepsilon_{\pi, t+1},
\end{aligned}
$$

where $\pi_{t+1}$ is the $\log$ inflation rate and $z_{t}$ is the one-period-ahead conditional expectation of the inflation rate.

The system is subject to four normally distributed, white noise shocks $\varepsilon_{m, t+1}, \varepsilon_{\pi, t+1}$, $\varepsilon_{x, t+1}$, and $\varepsilon_{z, t+1}$ that determine the innovations to the $\log \mathrm{SDF}$, the log inflation rate, and their conditional means. These shocks are cross-sectionally uncorrelated, with variances $\sigma_{m}^{2}$, $\sigma_{\pi}^{2}, \sigma_{x}^{2}$, and $\sigma_{z}^{2}$. It is important to note that $z_{t+1}$, the expected inflation rate, is affected by both a pure expected-inflation shock $\varepsilon_{z, t+1}$ and the shocks to the expected and unexpected 
$\log \operatorname{SDF} \varepsilon_{x, t+1}$ and $\varepsilon_{m, t+1}$. That is, innovations to expected inflation can be correlated with innovations in the log SDF, and hence with innovations in the short-term real interest rate. These correlations mean that nominal interest rates need not move one-for-one with expected inflation - that is, the Fisher hypothesis need not hold - and nominal bond prices can include an inflation risk premium as well as a real term premium.

We have written the model with a self-contained real sector (1) and a nominal sector (2) that is affected by shocks to the real sector. But this is merely a matter of notational convenience. Our model is a reduced form rather than a structural model, so it captures correlations among shocks to real and nominal interest rates but does not have anything to say about the true underlying sources of these shocks.

Campbell et al. (1997) note that $\varepsilon_{m, t+1}$ only affects the average level of the real term structure and not its average slope or time-series behavior. Accordingly, we can either drop it or identify its variance with an additional restriction. We follow the second approach and introduce equities in the model. We assume that the unexpected log return on equities is affected by shocks to both the expected and unexpected log SDF:

$$
r_{e, t+1}-\mathrm{E}_{t} r_{e, t+1}=\beta_{e x} \varepsilon_{x, t+1}+\beta_{e m} \varepsilon_{m, t+1}
$$

Campbell (1999) shows that this decomposition of the unexpected log equity return into a linear combination of the shocks to the expected and unexpected log SDF is consistent with a representative-agent endowment model where expected aggregate consumption growth follows an $\mathrm{AR}(1)$. From the fundamental pricing equation $1=\mathrm{E}_{t}\left[M_{t+1} R_{t+1}\right]$ and the lognormal 
structure of the model it is easy to show that the risk premium on equities, over a one-period riskless return $r_{1, t+1}$, is given by

$$
\begin{aligned}
\mathrm{E}_{t}\left[r_{e, t+1}-r_{1, t+1}\right]+\frac{1}{2} \operatorname{Var}_{t}\left(r_{e, t+1}-r_{1, t+1}\right) & =\operatorname{Cov}_{t}\left(r_{e, t+1}-r_{1, t+1},-m_{t+1}\right) \\
& =\beta_{m x} \beta_{e x} \sigma_{x}^{2}+\beta_{e m} \sigma_{m}^{2} .
\end{aligned}
$$

The variance term on the left hand side of (4) is a Jensen's Inequality correction that appears because we are working in logs, and the terms on the right hand side relate the risk premium

on equities to the covariance of equity returns with innovations in the SDF. This specification implies that the equity premium, like all other risk premia in the model, is constant over time. Thus it ignores the time-variation in the equity premium that is the subject of our earlier paper on long-run portfolio choice (Campbell and Viceira 1999).

\section{B. Derivation of the term structure}

We now show how our model can price default-free zero-coupon bonds that are either inflation-indexed (paying one unit of consumption at maturity) or nominal (paying one dollar at maturity). There is a direct link between the stochastic discount factor and the log return, or equivalently the log yield, on a one-period indexed bond: $r_{1, t+1}=-\log \mathrm{E}_{t}\left[M_{t+1}\right]$. Because $M_{t+1}$ is lognormal, we have that

$$
\begin{aligned}
r_{1, t+1} & =\mathrm{E}_{t}\left[-m_{t+1}\right]-\frac{1}{2} \operatorname{Var}_{t}\left[m_{t+1}\right] \\
& =x_{t}-\frac{1}{2}\left(\beta_{m x}^{2} \sigma_{x}^{2}+\sigma_{m}^{2}\right)
\end{aligned}
$$


Our assumptions on $m_{t+1}$ imply that the short-term real interest rate is stochastic, though riskless one period in advance. It inherits the stochastic properties of $x_{t+1}$, and follows an $\operatorname{AR}(1)$ process with mean $\mu-\left(\beta_{m x}^{2} \sigma_{x}^{2}+\sigma_{m}^{2}\right) / 2$ and persistence $\phi$.

Campbell et al. (1997), following Singleton (1990), Tong-sheng Sun (1992), and David Backus (1993), show that a lognormal, conditionally homoskedastic stochastic discount factor implies a pricing structure for log indexed bond yields which is affine in $x_{t+1}$. The $\log$ yield on an $n$-period indexed zero-coupon bond, $y_{n t}$, times bond maturity $n$, which equals minus the log price of the bond, $p_{n t}$, is given by

$$
n \cdot y_{n t}=-p_{n t}=A_{n}+B_{n} x_{t},
$$

where $A_{n}$ and $B_{n}$ are functions of bond maturity $n$ but not of time $t$, and satisfy the following recursive equations:

$$
\begin{aligned}
B_{n} & =1+\phi_{x} B_{n-1}=\frac{1-\phi_{x}^{n}}{1-\phi_{x}} \\
A_{n}-A_{n-1} & =\left(1-\phi_{x}\right) \mu_{x} B_{n-1}-\frac{1}{2}\left[\left(\beta_{m x}+B_{n-1}\right)^{2} \sigma_{x}^{2}+\sigma_{m}^{2}\right],
\end{aligned}
$$

and $A_{0}=B_{0}=0$. An implication of (6) is that yields on indexed bonds of different maturities are perfectly correlated with each other.

The one-period log return on an $n$-period indexed zero-coupon bond is by definition $\left(p_{n-1, t+1}-p_{n, t}\right)$. Combining this expression with (6) and (7), the excess return over the one-period log interest rate is

$$
r_{n, t+1}-r_{1, t+1}=-\frac{1}{2} B_{n-1}^{2} \sigma_{x}^{2}-\beta_{m x} B_{n-1} \sigma_{x}^{2}-B_{n-1} \varepsilon_{x, t+1},
$$


so the $n$-period bond is risky, with a sensitivity $B_{n-1}$ to real interest rate shocks and a risk premium given by

$$
\begin{aligned}
\mathrm{E}_{t}\left[r_{n, t+1}-r_{1, t+1}\right]+\frac{1}{2} \operatorname{Var}_{t}\left(r_{n, t+1}-r_{1, t+1}\right) & =\operatorname{Cov}_{t}\left(r_{n, t+1}-r_{1, t+1},-m_{t+1}\right) \\
& =-\beta_{m x} B_{n-1} \sigma_{x}^{2} .
\end{aligned}
$$

The variance term on the left hand side of (9) is a Jensen's Inequality correction that appears because we are working in logs. The conditional covariance of the excess bond return with the $\log \mathrm{SDF}$ determines the risk premium. In our homoskedastic model the conditional covariance is constant through time but dependent on the bond maturity; thus the expectations hypothesis of the term structure holds for indexed bonds. It is important to realize that constant risk premia do not imply constant investment opportunities because real interest rates are stochastic in our model.

Since $B_{n-1}>0$, the risk premium has the opposite sign to $\beta_{m x}$. With a positive $\beta_{m x}$, longterm indexed bonds pay off when the marginal utility of consumption for a representative investor is high, that is, when wealth is most desirable. In equilibrium, these bonds have a negative risk premium. With a negative $\beta_{m x}$, on the other hand, long-term indexed bonds pay off when the marginal utility of consumption for a representative investor is low, and so in equilibrium they have a positive risk premium.

Equations (8) and (9) imply that the Sharpe ratio for indexed bonds is $-\beta_{m x} \sigma_{x}$, which is independent of bond maturity. The invariance of the Sharpe ratio to bond maturity follows from the one-factor structure of the real sector of the model. The ratio of the risk premium 
to the variance of the excess return, which determines a myopic investor's allocation to longterm bonds, is $-\beta_{m x} / B_{n-1}$. This does depend on bond maturity but not on the volatility of the real interest rate.

The pricing of nominal bonds follows the same steps as the pricing of indexed bonds. The relevant stochastic discount factor for nominal bonds is the nominal SDF $M_{t+1}^{\$}$, whose $\log$ is given by:

$$
m_{t+1}^{\$}=m_{t+1}-\pi_{t+1}
$$

Since both $M_{t+1}$ and $\Pi_{t+1}$ are jointly lognormal and homoskedastic, $M_{t+1}^{\$}$ is also lognormal. The $\log$ nominal return on a one-period nominal bond is $r_{1, t+1}^{\$}=-\log \mathrm{E}_{t}\left[M_{t+1}^{\$}\right]$, which implies that $r_{1, t+1}^{\$}$ is a linear combination of the expected log real SDF and expected inflation given in an Appendix available from the authors upon request. ${ }^{6}$

The $\log$ price of an $n$-period nominal zero-coupon bond, $p_{n, t}^{\$}$, also has an affine structure. It is a linear combination of $x_{t}$ and $z_{t}$ whose coefficients are time-invariant, though they vary with the maturity of the bond:

$$
-p_{n, t}^{\$}=A_{n}^{\$}+B_{1, n}^{\$} x_{t}+B_{2, n}^{\$} z_{t} .
$$

The Appendix gives expressions for the coefficients $A_{n}^{\$}, B_{1, n}^{\$}$ and $B_{2, n}^{\$}$.

Since nominal bond prices are driven by shocks to both real interest rates and inflation, they have a two-factor structure rather than the single-factor structure of indexed bond prices. Inflation affects the excess return on an $n$-period nominal bond over the one-period 
nominal interest rate, so risk premia in the nominal term structure include compensation for inflation risk. Like all other risk premia in the model, however, the risk premia on nominal bonds are constant over time; thus the expectations hypothesis of the term structure holds for nominal as well as for real bonds.

\section{The term structure of interest rates in the US}

We estimate the two-factor term structure model using data on US nominal interest rates, equities and inflation. We use nominal zero-coupon yields at maturities 3 months, 1 year, 3 years, and 10 years from J. Huston McCulloch and Heon-Chul Kwon (1993), updated by Frank F. Gong and Eli M. Remolona (1996a,b). We take data on equities from the Indices files on the CRSP tapes, using the value-weighted return, including dividends, on the NYSE, AMEX and NASDAQ markets. For inflation, we use a Consumer Price Index that retrospectively incorporates the rental-equivalence methodology, thereby avoiding any direct effect of nominal interest rates on measured inflation. The Appendix shows that estimation results are extremely similar if we instead use the personal consumption expenditure (PCE) deflator to measure inflation. Although the raw data are available monthly, we construct a quarterly data set in order to reduce the influence of high-frequency noise in inflation and short-term movements in interest rates. We begin our sample in 1952, just after the Fed-Treasury Accord that dramatically altered the time-series behavior of nominal interest rates. Our data end in 1996. 
To avoid the implication of the model that bond returns are driven by only two common factors, so that all bond returns can be perfectly explained by any two bond returns, we assume that bond yields are measured with error. The errors in yields are normally distributed, serially uncorrelated, and uncorrelated across bonds. Then the term structure model becomes a classic state-space model in which unobserved state variables $x_{t}$ and $z_{t}$ follow a linear process with normal innovations and we observe linear combinations of them with normal errors. The model can be estimated by maximum likelihood using a Kalman filter to construct the likelihood function (Andrea Berardi 1997, Andrew Harvey 1989, George Pennacchi 1991, Gong and Remolona 1996a,b, Silverio Foresi et al. 1997). This is an attractive alternative to the Generalized Method of Moments used to estimate term structure models by Michael R. Gibbons and Krishna Ramaswamy (1993) and others.

In Table 1 we report parameter estimates for the period 1952-96 and the period 198396. Interest rates were unusually high and volatile in the 1979-82 period, during which the Federal Reserve Board under Paul Volcker was attempting to reestablish the credibility of anti-inflationary monetary policy and was experimenting with monetarist operating procedures. Many authors have argued that real interest rates and inflation have behaved differently in the monetary policy regime established since 1982 by Federal Reserve chairmen Volcker and Alan Greenspan (see for example Richard Clarida et al. 1998). Accordingly we report separate estimates for the period starting in 1983 in addition to the full sample period. 
The parameter values in Table 1 are restricted maximum likelihood estimates of the model. Unrestricted maximum likelihood estimates fit the data well in the 1952-96 sample period, but they deliver implausibly low means for short-term nominal and real interest rates in the 1983-96 sample period. (The model does not necessarily fit the sample means because the same parameters are used to fit both time-series and cross-sectional behavior; thus the model can trade off better fit elsewhere for worse fit of mean short-term interest rates.) Accordingly we require that the model exactly fit the sample means of nominal interest rates and inflation. This restriction hardly reduces the likelihood at all in 1952-96, and even in 1983-96 it cannot be rejected at conventional significance levels.

The first two columns of Table 1 report parameters and asymptotic standard errors for the period 1952-96. All parameters are in natural units, so they are on a quarterly basis. We estimate a moderately persistent process for the real interest rate; the persistence coefficient $\phi_{x}$ is 0.87 , implying a half-life for shocks to real interest rates of about 5 quarters. The expected inflation process is much more persistent, with a coefficient $\phi_{z}$ of 0.9992 that implies a half-life for expected inflation shocks of over two centuries! Of course, the model also allows for transitory noise in realized inflation.

The bottom of Table 1 reports the implications of the estimated parameters for the means and standard deviations of real interest rates, nominal interest rates, and inflation, measured in percent per year. The implied mean log yield on an indexed three-month bill is 1.39 percent for the $1952-96$ sample period. Taken together with the mean log yield on a 
nominal three-month bill of 5.50 percent and the mean log inflation rate of 3.77 percent (both restricted to equal the sample means over this period), and adjusting for Jensen's Inequality using one-half the conditional variance of log inflation, the implied inflation risk premium in a three-month nominal Treasury bill is 35 basis points. This fairly substantial risk premium is explained by the significant positive coefficient $\beta_{\pi x}$ and the significant negative coefficient $\beta_{\pi m}$ in Table $1 .^{7}$

Risk premia on long-term indexed bonds, relative to a three-month indexed bill, are determined by the parameter $\beta_{m x}$. This is negative and significant, implying positive risk premia on long-term indexed bonds and an upward sloping term structure of real interest rates. Risk premia on nominal bonds, relative to indexed bonds, are determined by the inflation-risk parameters $\beta_{z x}$ and $\beta_{z m}$. The former is positive but statistically insignificant, while the latter is negative and significant. Both point estimates imply positive inflation risk premia on nominal bonds relative to indexed bonds.

The parameters in Table 1 can also be used to calculate the volatility of the log stochastic discount factor. From (1), the variance of $m_{t+1}$ is $\sigma_{x}^{2} /\left(1-\phi_{x}^{2}\right)+\beta_{m x}^{2} \sigma_{x}^{2}+\sigma_{m}^{2}$. The estimates in Table 1 imply a large quarterly standard deviation of 0.33 , consistent with the literature on volatility bounds for the stochastic discount factor (Lars P. Hansen and Ravi Jagannathan 1991, John H. Cochrane and Hansen 1992). When financial markets are complete, the discounted marginal utility growth of each investor must be equal to the stochastic discount factor. Therefore the consumption and portfolio solutions we report later in the paper 
for the complete-markets case imply highly volatile marginal utilities, due either to volatile consumption or high risk aversion. This is a manifestation of the equity premium puzzle of Rajnish Mehra and Edward Prescott (1985) in our microeconomic model with exogenous asset returns and endogenous consumption.

Table 2 explores the term-structure implications of our estimates in greater detail. The table compares implied and sample moments of term structure variables, measured in percent per year. It also reports standard errors for the implied moments, calculated using the delta method. Panel A of Table 2 reports sample moments for returns and yields on nominal bonds, together with the moments implied by our estimated model; panel B shows comparable implied moments for indexed bonds, and panel $\mathrm{C}$ reports sample and implied moments for equities. Row 1 of the table gives Jensen's-Inequality-corrected average excess returns on $n$ period nominal bonds over 1-period nominal bonds, while row 2 gives the standard deviations of these excess returns. Row 3 reports annualized Sharpe ratios for nominal bonds, the ratio of row 1 to row 2 . Row 4 reports mean nominal yield spreads and row 5 reports the standard deviations of nominal yield spreads. Rows 6 through 10 repeat these moments for indexed bonds. Note that the reported risk premia and Sharpe ratios for nominal and indexed bonds are not directly comparable because they are measured relative to different short-term assets, nominal and indexed respectively.

A comparison of the model implications in rows 1 and 6 shows that 10 -year nominal bonds have a risk premium over three-month nominal bills of 1.97 percent per year, while 10-year 
indexed bonds have a risk premium over three-month indexed bills of 1.35 percent per year. These numbers, together with the 35-basis-point risk premium on three-month nominal bills over three-month indexed bills, imply a 10-year inflation risk premium (the risk premium on 10-year nominal bonds over 10-year indexed bonds) slightly above 1.1 percent. This estimate is consistent with the rough calculations in Campbell and Shiller (1996).

Rows 2 and 7 show that nominal bonds are much more volatile than indexed bonds; the difference in volatility increases with maturity, so that 10-year nominal bonds have a standard deviation three times greater than 10-year indexed bonds. This difference in volatility makes the Sharpe ratio for indexed bonds in row 8 considerably higher than the Sharpe ratio for nominal bonds in row 3. Since indexed bond returns are generated by a single-factor model, the Sharpe ratio for indexed bonds is independent of maturity at 0.37. The Sharpe ratio for nominal bonds declines with maturity; short-term nominal bonds have a ratio close to that for indexed bonds, but the Sharpe ratio for 10-year nominal bonds is only 0.17 . These numbers imply that in our portfolio analysis, investors with low risk aversion will have a strong myopic demand for indexed bonds.

Table 2 can also be used to evaluate the empirical fit of the model. A comparison of the model's implied moments with the sample moments for nominal bonds shows that the model fits the volatility of excess nominal bond returns and changes in yields extremely well. The model somewhat overstates the average excess nominal bond return and the nominal Sharpe ratio, but this can be attributed in part to the upward drift in interest rates over the 
1952-96 sample period which biases downward the sample means. The standard errors for implied volatilities are small, while the standard errors of implied mean excess returns are large. This reflects the well-known result that it is much harder to obtain precise estimates of first moments than of second moments.

Another way to judge the fit of the model is to ask how much of the variability of bond yields, or bond returns, is accounted for by the structural parameters as opposed to the white-noise measurement errors we have allowed in each bond yield. The estimated variances of measurement errors (not reported in Table 1) are zero for 1-year and 10-year bonds and are extremely small for 3-month bills and 3-year bonds. Measurement errors are estimated to account for less than 0.5 percent of the variance of 3-month and 3-year bond yields and less than 5 percent of the variance of 3-year bond returns. This reflects the fact that bond yields are highly persistent at all maturities, so the model fits them primarily with persistent structural processes rather than white-noise measurement errors.

Overall the model appears to provide a good description of the nominal US term structure considering its parsimony and the fact that we have forced it to fit both time-series and crosssectional features of the data.

Rows 11, 12, and 13 of Table 2 report summary statistics for equities: the annualized Jensen's-Inequality-corrected average excess returns on equities relative to nominal bills, the standard deviation of these excess returns, and their Sharpe ratio. The model fits the standard deviation of equities extremely well but overpredicts the equity premium and the 
Sharpe ratio for equities. The implied Sharpe ratio of 0.57 implies that investors with low risk aversion will have an extremely large myopic demand for equities; this is again a manifestation of the equity premium puzzle.

The right hand sides of Tables 1 and 2 repeat these estimates for the Volcker-Greenspan period 1983-96. Many of the parameter estimates are quite similar; however we find that in this period real interest rates are much more persistent, with $\phi_{x}=0.986$ and an implied half-life for real interest rate shocks of about 12 years. The expected inflation process now mean-reverts much more rapidly, with $\phi_{z}=0.860$ implying a half-life for expected inflation shocks of about 5 quarters. These results are consistent with the notion that since the early 1980's the Federal Reserve has more aggressively controlled inflation at the cost of greater long-term variation in the real interest rate (Clarida et al. 1998). The increase in real-interest-rate persistence increases the risk premia on indexed and nominal bonds, but it also greatly increases the volatility of indexed bond returns so the Sharpe ratio for indexed bonds is lower at 0.15 . In the remainder of the paper we present portfolio choice results based on our full-sample estimates for the period 1952-96, but we also discuss results for the 1983-96 period where they are importantly different. 


\section{The Demand for Indexed Bonds}

\section{A. Investor preferences and the budget constraint}

The investor is infinite-lived, lives off her financial wealth and faces the investment environment described above. We assume that her preferences are described by the recursive utility proposed by Epstein and Zin (1989) and Weil (1989):

$$
U\left(C_{t}, \mathrm{E}_{t} U_{t+1}\right)=\left\{(1-\delta) C_{t}^{\frac{1-\gamma}{\theta}}+\delta\left(\mathrm{E}_{t} U_{t+1}^{1-\gamma}\right)^{\frac{1}{\theta}}\right\}^{\frac{\theta}{1-\gamma}}
$$

where $\delta<1$ is the discount factor, $\gamma>0$ is the coefficient of relative risk aversion, $\psi>0$ is the elasticity of intertemporal substitution, and $\theta \equiv(1-\gamma) /(1-1 / \psi)$. The recursive utility function (12) reduces to the standard time-separable, power utility function with relative risk aversion $\gamma$ when $\psi=1 / \gamma$. In this case $\theta=1$.

Recursive preferences are useful because they allow us to separate the investor's attitude towards risk from her attitude towards intertemporal substitution of consumption over time. This separation is particularly important in our framework, where the short-term interest rate moves over time giving the investor an incentive to change her planned consumption growth rate.

The investor maximizes (12) subject to the intertemporal budget constraint

$$
W_{t+1}=R_{p, t+1}\left(W_{t}-C_{t}\right)
$$

where $R_{p, t+1}$ is the gross return at time $t+1$ on her portfolio at time $t$. 
Epstein and Zin $(1989,1991)$ have shown that when the budget constraint is given by (13), the optimal portfolio and consumption policies must satisfy the following Euler equation for any asset $i$ :

$$
1=\mathrm{E}_{t}\left[\left\{\delta\left(\frac{C_{t+1}}{C_{t}}\right)^{-\frac{1}{\psi}}\right\}^{\theta} R_{p, t+1}^{-(1-\theta)} R_{i, t+1}\right]
$$

When $i=p$, (14) reduces to:

$$
1=\mathrm{E}_{t}\left[\left\{\delta\left(\frac{C_{t+1}}{C_{t}}\right)^{-\frac{1}{\psi}} R_{p, t+1}\right\}^{\theta}\right]
$$

Dividing (12) by $W_{t}$ and using the budget constraint we obtain the following expression for utility per unit of wealth:

$$
V_{t} \equiv U_{t} / W_{t}=\left\{(1-\delta)\left(\frac{C_{t}}{W_{t}}\right)^{1-\frac{1}{\psi}}+\delta\left(1-\frac{C_{t}}{W_{t}}\right)^{1-\frac{1}{\psi}}\left(\mathrm{E}_{t}\left[V_{t+1}^{1-\gamma} R_{p, t+1}^{1-\gamma}\right]\right)^{\frac{1}{\theta}}\right\}^{\frac{1}{1-\psi}}
$$

Epstein and Zin $(1989,1991)$ show that the maximized $V_{t}$, the value function per unit of wealth, can be written as a power function of $(1-\delta)$ and the consumption-wealth ratio:

$$
V_{t}=(1-\delta)^{-\frac{\psi}{1-\psi}}\left(\frac{C_{t}}{W_{t}}\right)^{\frac{1}{1-\psi}} .
$$

Two special cases are worth noting. First, as $\psi$ approaches one, the exponents in (17) increase without limit. The value function has a finite limit, however, because the ratio $C_{t} / W_{t}$ approaches $(1-\delta)$ as shown by Giovannini and Weil (1989). Second, as $\psi$ approaches zero, $V_{t}$ approaches $C_{t} / W_{t}$. A consumer who is extremely reluctant to substitute intertemporally consumes the annuity value of wealth each period, and this consumer's utility per dollar is the annuity value of the dollar. 


\section{B. Loglinear approximation of the model}

At this point, to simplify the analysis and build intuition we assume that there are only two bonds available to the investor, a one-period indexed bond and an $n$-period indexed bond. Given the one-factor structure of our model for indexed bonds, this is equivalent to providing the investor with a complete indexed term structure. Under this assumption, $R_{p, t+1}$ is equal to

$$
R_{p, t+1}=\alpha_{n, t}\left(R_{n, t+1}-R_{1, t+1}\right)+R_{1, t+1}
$$

where $\alpha_{n, t}$ is the fraction of the investor's savings allocated to the $n$-period indexed bond at time $t$. In Section III below we generalize the model to include nominal bonds and equities.

In order to find optimal savings and the optimal allocations to the two bonds, we adopt an approximate analytical solution method. The first step is to characterize $\alpha_{n, t}$, the optimal allocation to the $n$-period bond, by combining a second-order log-linear approximation to the Euler equation with a first-order approximation to the intertemporal budget constraint. We then guess a form for the optimal consumption and portfolio policies and show that policies of this form satisfy the approximate Euler equation and budget constraint. Finally we use the method of undetermined coefficients to identify the coefficients of the optimal policies from the primitive parameters of the model. By using a second-order expansion of the $\log$ Euler equation we account for second-moment effects in the model.

Following Campbell (1993, 1996), Campbell and Viceira (1999), and Fernando Restoy (1992), we first $\log$-linearize the Euler equation (14) for $i=n$ and $i=1$, where asset 1 is 
the short-term riskless asset. Subtracting the log-linearized Euler equation for the riskless asset from the log-linearized equation for asset $n$, we find:

$$
\begin{aligned}
\mathrm{E}_{t}\left[r_{n, t+1}-r_{1, t+1}\right]+\frac{1}{2} \operatorname{Var}_{t}\left(r_{n, t+1}\right)= & \left(\frac{\theta}{\psi}\right) \operatorname{Cov}_{t}\left(\Delta c_{t+1}, r_{n, t+1}\right) \\
& +(1-\theta) \operatorname{Cov}_{t}\left(r_{p, t+1}, r_{n, t+1}\right)
\end{aligned}
$$

where lowercase letters denote variables in logs and $\Delta$ is the first-difference operator. This expression says that the risk premium on asset $n$ is a weighted average of the asset's covariance with consumption growth divided by $\psi$, and the asset's covariance with the portfolio return. The weights are $\theta$ and $(1-\theta)$, respectively; in the case of power utility, $\theta=1$ and only the consumption covariance enters the Euler equation. We obtain (19) from (14) by using both a second-order Taylor approximation around the conditional mean of $\left\{r_{p, t+1}, \Delta c_{t+1}\right\}$ and the approximation $\log (1+x) \approx x$ for small $x$. Equation (19) holds exactly if consumption growth and the return on wealth have a joint conditional lognormal distribution. We show later that our approximate solution implies just such a distribution.

We can log-linearize the Euler equation (15) in a similar fashion. After reordering terms, we obtain the well-known equilibrium linear relationship between expected log consumption growth and the expected log return on wealth:

$$
\mathrm{E}_{t} \Delta c_{t+1}=\psi \log \delta+v_{p, t}+\psi \mathrm{E}_{t} r_{p, t+1}
$$

where the term $v_{p, t}$ is an intercept proportional to the conditional variance of log consumption 
growth in relation to log portfolio returns:

$$
v_{p, t}=\frac{1}{2}\left(\frac{\theta}{\psi}\right) \operatorname{Var}_{t}\left(\Delta c_{t+1}-\psi r_{p, t+1}\right) .
$$

In general this intercept is time-varying, but in our model it becomes a constant. These equations, like (19), hold exactly if consumption and asset returns are jointly conditionally lognormal.

Taking the return on wealth as given, we can also log-linearize the intertemporal budget constraint (13) around the mean log consumption-wealth ratio:

$$
\Delta w_{t+1} \approx r_{p, t+1}+\left(1-\frac{1}{\rho}\right)\left(c_{t}-w_{t}\right)+k,
$$

where $k=\log (\rho)+(1-\rho) \log (1-\rho) / \rho$, and $\rho=1-\exp \left\{\mathrm{E}\left(c_{t}-w_{t}\right)\right\}$ is a log-linearization parameter. Note that $\rho$ is endogenous in that it depends on the average log consumptionwealth ratio, which is unknown until the model has been solved. Campbell (1993) proposes the approximation (22) and shows that it holds exactly if the consumption-wealth ratio is constant over time. Alberto Giovannini and Weil (1989) show that if the elasticity of intertemporal substitution $\psi=1$, then the consumption-wealth ratio is constant at $(1-\delta)$; in this special case our solution is exact and we know that $\rho=\delta$.

Finally, equation (18) allows us to approximate $r_{p, t+1}$, the log return on wealth, as follows:

$$
r_{p, t+1}=\alpha_{n, t}\left(r_{n, t+1}-r_{1, t+1}\right)+r_{1, t+1}+\frac{1}{2} \alpha_{n, t}\left(1-\alpha_{n, t}\right) \operatorname{Var}_{t}\left(r_{n, t+1}\right) .
$$

This is a discrete-time version of the log return on wealth in continuous time, where Ito's 
Lemma can be applied to equation (18). The accuracy of this approximation increases as the time interval shrinks.

Combining the trivial equality

$$
\Delta c_{t+1}=\left(c_{t+1}-w_{t+1}\right)-\left(c_{t}-w_{t}\right)+\Delta w_{t+1}
$$

with equations (19), (22), and (23) and the definition of $\theta$ we find that

$$
\begin{aligned}
\alpha_{n, t}= & \frac{1}{\gamma} \frac{\mathrm{E}_{t}\left[r_{n, t+1}-r_{1, t+1}\right]+\frac{1}{2} \operatorname{Var}_{t}\left(r_{n, t+1}\right)}{\operatorname{Var}_{t}\left(r_{n, t+1}\right)} \\
& -\left(\frac{1}{1-\psi}\right)\left(\frac{\gamma-1}{\gamma}\right) \frac{\operatorname{Cov}_{t}\left(r_{n, t+1}, c_{t+1}-w_{t+1}\right)}{\operatorname{Var}_{t}\left(r_{n, t+1}\right)} .
\end{aligned}
$$

This equation was first derived by Restoy (1992). The first term is the myopic component of asset demand; it is proportional to the risk premium on the $n$-period bond and the reciprocal of the coefficient of relative risk aversion. The second term is Merton's (1969, 1971, 1973) intertemporal hedging demand. It reflects the strategic behavior of the investor who wishes to hedge against future adverse changes in investment opportunities, as summarized by the consumption-wealth ratio. In our setup the investment opportunity set is time-varying because interest rates are time-varying (although expected excess returns are constant); accordingly the investor may want to hedge her consumption against adverse changes in interest rates. Intertemporal hedging demand is zero when risk aversion $\gamma=1$, but as $\gamma$ increases myopic demand shrinks to zero and hedging demand does not. In the limit as $\gamma$ becomes arbitrarily large, hedging demand accounts for all the demand for the risky asset. 
An important special case arises when the elasticity of intertemporal substitution is unity. As $\psi \rightarrow 1$, the $\log$ consumption-wealth ratio becomes constant so the covariance of asset returns with this ratio approaches zero. However the covariance is divided by $1-\psi$, which also approaches zero. Giovannini and Weil (1989), by taking appropriate limits, have shown that portfolio choice is not myopic in this case even though the consumption-wealth ratio is constant. The solution presented in this paper is exact for the case $\psi=1$.

\section{An explicit solution}

Equation (25) is recursive in the sense that it relates current portfolio decisions to future consumption and portfolio decisions. In order to get a complete solution to the model we need to derive consumption and portfolio rules that depend only on current state variables. We do this by guessing that the consumption function takes the form

$$
c_{t}-w_{t}=b_{0}+b_{1} x_{t}
$$

Calculations summarized in the Appendix verify this guess and show that the coefficients are given by

$$
\begin{aligned}
b_{0}= & \frac{\rho}{1-\rho}\left[\frac{(1-\psi)(1-\gamma)}{2 \gamma}\left(\beta_{m x}+\frac{\rho}{1-\rho \phi_{x}}\right)^{2} \sigma_{x}^{2}-\frac{1}{2}(1-\psi) \sigma_{m}^{2}\right. \\
& \left.-\psi \log \delta+k+\mu(1-\phi) \frac{\rho(1-\psi)}{1-\rho \phi_{x}}\right]
\end{aligned}
$$

and

$$
b_{1}=(1-\psi) \frac{\rho}{1-\rho \phi_{x}} .
$$


In addition, the optimal portfolio share in the risky asset is constant over time and can be written as

$$
\alpha_{n t}=\alpha_{n}=\frac{-1}{\gamma B_{n-1}}\left[\beta_{m x}+(1-\gamma) \frac{\rho}{1-\rho \phi_{x}}\right]
$$

These solutions are analytical, given the $\log$-linearization parameter $\rho$. But $\rho$ itself is a nonlinear function of the coefficients $b_{0}$ and $b_{1}$, since $\rho=1-\exp \left\{\mathrm{E}\left[c_{t}-w_{t}\right]\right\}=1-\exp \left\{b_{0}+\right.$ $\left.b_{1} \mu_{x}\right\}$. Equations $(27),(28)$, and the expression for $\rho$ define implicitly a nonlinear mapping of $\rho$ onto itself which has an analytical solution only in the case $\psi=1$, when $\rho=\delta$. In all other cases we solve for $\rho$ numerically using a simple recursive algorithm. We set $\rho$ to some initial value (typically $\rho=\delta$ ) and compute the coefficients of the optimal policies; given these coefficients we compute a new value for $\rho$, from which we obtain a new set of coefficients, and so forth. We continue until the difference between two consecutive values of $\rho$ is less than $10^{-4}$. This recursion converges very rapidly to a number between zero and one whenever the value function of the model is finite.

Equations (26) and (28) show that the log consumption-wealth ratio is linear in the shortterm real interest rate (since $x_{t}$ is linearly related to $r_{1, t+1}$ ). The response of consumption to the interest rate depends on the investor's elasticity of intertemporal substitution, but does not depend directly on her relative risk aversion. The risk aversion coefficient affects the dynamic behavior of consumption only indirectly through its effect on the log-linearization parameter $\rho$. In the Appendix we show that this indirect effect is empirically very small.

The consumption-wealth ratio increases with the interest rate if $\psi<1$ and falls with the 
interest rate if $\psi>1$. An increase in the short-term real interest rate is equivalent to an improvement in the investment opportunity set, and it has both income and substitution effects. An investor with low $\psi$ is reluctant to substitute intertemporally, and for her the income effect dominates, leading her to increase her consumption relative to her wealth. Conversely, the substitution effect dominates for an investor with high $\psi>1$. This investor will reduce present consumption when the interest rate increases. Both income and substitution effects on consumption are stronger, the more persistent is the improvement in investment opportunities - the closer is $\phi$ to one. The consumption-wealth ratio is constant only when $\psi=1$, in which case $c_{t}-w_{t}$ equals $\log (1-\delta)$.

Equation (29) shows that the optimal portfolio allocation to the long-term bond is constant over time and independent of the level of the short-term interest rate. The portfolio allocation depends on the bond maturity, on the persistence of the short-term interest rate, and on the investor's relative risk aversion, but does not depend directly on her elasticity of intertemporal substitution. The elasticity of intertemporal substitution affects portfolio choice only indirectly through its effect on the log-linearization parameter $\rho$, and we show in the Appendix that this indirect effect is empirically very small.

The first term inside the brackets in (29) represents the myopic demand for long-term bonds, while the second term represents the intertemporal hedging demand. The myopic demand depends on the ratio of mean excess bond return to variance, $-\beta_{m x} / B_{n-1}$, divided by the coefficient of risk aversion $\gamma$. Thus myopic demand goes to zero as risk aversion 
increases.

The intertemporal hedging demand for bonds is zero when $\gamma=1$. Investors with unit relative risk aversion are "myopic investors" who demand long-term bonds exclusively for their risk premium. Investors with $\gamma>1$, however, have a positive intertemporal hedging demand. Long-term bonds have high returns when interest rates fall, that is, when future investment opportunities deteriorate, so conservative investors use them to hedge investment-opportunity risk..$^{8}$

It is interesting to consider what happens in the limit as the investor becomes infinitely risk-averse. The optimal portfolio for an infinitely conservative investor is one natural way to define a "riskless" asset. Financial economists conventionally take a short-term perspective and treat a one-period indexed bond as riskless. A one-period nominal bond is a good substitute for a one-period indexed bond (Viard 1993), and thus by extension the riskless asset is often identified with a short-term nominal asset such as a Treasury bill. In a world with time-varying interest rates, however, only the current short-term real interest rate is riskless; future short-term real interest rates are uncertain. This means that a strategy of investing in one-period bonds is risky for an infinite-lived investor.

In the Appendix, we show that an infinite-lived investor who is infinitely risk-averse and infinitely reluctant to substitute consumption intertemporally chooses a portfolio of indexed bonds that is equivalent to an indexed perpetuity. Such a portfolio finances a riskless, constant stream of consumption, so it is suitable for an infinitely conservative long-term 
investor despite its unstable capital value. In this sense an indexed perpetuity, not a oneperiod indexed bond, is the riskless asset in our model. ${ }^{9}$

An investor who is infinitely risk-averse but whose elasticity of intertemporal substitution in consumption is nonzero holds a slightly different bond portfolio, because this investor wishes to tilt the consumption growth path in response to interest-rate incentives and therefore allows some variability in consumption growth. This is possible in a recursive-utility framework because marginal utility is determined not only by current consumption but also by discounted future utility. Hence even an infinitely risk-averse investor may be willing to accept some variability in current consumption if it is compensated by movements in future utility that leave current marginal utility unchanged. The empirical results in the Appendix show that the deviation from the real-perpetuity portfolio is very small, consistent with the general result that the elasticity of intertemporal substitution has only small effects on the optimal portfolio policy.

A noteworthy feature of the portfolio solution in (29) is that it does not restrict the portfolio share of the risky asset to lie between zero and one. In discrete time with lognormally distributed risky asset returns, portfolios with short positions $(\alpha<0)$ or leverage $(\alpha>1)$ permit bankruptcy which would produce infinitely negative utility. In continuous time with diffusions for asset prices, this problem disappears as the investor is able to continually rebalance her portfolio and can adjust her position at any time to avoid bankruptcy. Our approximate solution implicitly relies on this property of continuous-time models as we 
have replaced the exact discrete-time portfolio return by the approximation (29) which holds exactly in continuous time.

While the possibility of bankruptcy may seem troubling, in section III below we show how to rule it out by imposing short-sales and leverage constraints. Also, George Chacko and Viceira (1999) study our consumption and portfolio choice problem in a continuoustime setting. They find that continuous time rules out bankruptcy but changes neither the form of the solution nor the nature of the approximation needed to find it. Our discretetime solution (29) converges to their continuous-time solution as the model's time interval shrinks.

Our model assumes that the state variable $x_{t}$ follows a homoskedastic process. This has the advantage that the Kalman filter is an optimal estimator of the model's parameters even if the underlying model has a shorter time interval than the data measurement interval or is set in continuous time (A.R. Bergstrom 1984, Campbell and Albert S. Kyle 1993). It would be straightforward, however, to solve the model under the alternative assumption that $x_{t}$ follows a square-root process. In this case the optimal consumption function would still have the form (26), and the optimal portfolio share in the risky asset would still be constant. Equation (25) shows why $\alpha_{n}$ remains constant under this form of conditional heteroskedasticity. The numerator of $\alpha_{n}$ in (25) is a linear combination of the expected excess return on the risky asset and the conditional covariance of the excess return with the log consumption-wealth ratio, while the denominator is proportional to the conditional variance 
of the excess return. If $x_{t}$ follows a square-root process, the conditional mean and variance of the excess return are proportional to $x_{t}$, while (26) implies that the conditional covariance is also proportional to $x_{t}$. Therefore, the ratio (25) must be a constant independent of $x_{t}$.

Some further properties of the solution follow from the fact that, even with only two assets, markets are complete with respect to real-interest-rate risk because our real termstructure model has only one factor. Here we state these properties briefly, and we refer the reader to the Appendix for full details. First, with complete markets the investor can combine short- and long-term bonds so that the return on her bond portfolio is independent of the maturity of the long-term bond traded in the market. That is, she can synthesize her own optimal long-term bond, with the maturity optimal for her given her risk preferences. The interest-rate sensitivity of the portfolio is $\alpha_{n} B_{n-1}$, and equation (29) shows that this is independent of bond maturity $n$.

Second, if real-interest-rate variation is the only source of risk, then markets are complete with respect to all sources of risk. We can explore this case by setting $\sigma_{m}^{2}=0$ so that $\varepsilon_{m, t+1}$ drops from the definition of $m_{t+1}$ in (1). In this case the SDF is unique. Since the intertemporal marginal rate of substitution (IMRS) of any investor can be used as a valid SDF, it follows that all investors must have the same IMRS which must equal the SDF we specified exogenously for our term structure model. This provides a check on the internal consistency of our solution. Using (14) to express the investor's IMRS as a function of consumption growth and the portfolio return, it is straightforward to show that 
$\log \left(I M R S_{t+1}\right)=m_{t+1}$

Third, Cox and Chi-fu Huang (1989) have proposed an alternative solution method for intertemporal consumption and portfolio choice problems with complete markets. They work in continuous time and show that with complete markets, optimally invested wealth must satisfy a partial differential equation (PDE). Unfortunately this PDE does not generally have a closed-form solution. We show in the Appendix that our solution methodology is equivalent to a discrete-time version of the Cox-Huang approach; our loglinear approximation allows us to solve the discrete-time equivalent of the Cox-Huang PDE in closed form. ${ }^{10}$

\section{Empirical properties of the solution}

Table 3 explores the empirical properties of the portfolio solution (29) using the bondpricing parameters estimated in Table 1 for the period 1952-96. Qualitative results are similar for the 1983-96 period reported in the Appendix. An understanding of these properties will help us interpret solutions in more realistic, but also more complex, settings with multiple long-term assets and portfolio constraints. Results for these settings are also reported in Table 3 and in Table 4, and they are discussed in section III below.

We compute optimal portfolio rules for investors with the same time discount rate (4 percent) but different coefficients of relative risk aversion of $0.75,1,2,5,10$, and 5000 (effectively almost infinite). To save space we present results only for an elasticity of intertemporal substitution equal to one, since this coefficient has only a negligible effect on 
portfolio allocation. The Appendix presents complete results for elasticities equal to the reciprocals of the risk aversion coefficients we consider.

The second column of Table 3 reports the percentage portfolio share of a ten-year zerocoupon indexed bond. Since indexed bonds have attractive Sharpe ratios, we find that investors with low risk aversion have a very large myopic demand for long-term indexed bonds; they want to invest many times their total wealth in these bonds and borrow at the short-term riskless interest rate. As risk aversion increases, the demand for indexed bonds gradually declines, but it does not go to zero because highly risk averse investors have a positive intertemporal hedging demand for long-term indexed bonds. The numbers in parentheses below each allocation clarify this point by reporting the share of intertemporal hedging demand in the total demand for long-term bonds. This share rises from zero when $\gamma=1$ to 100 percent when $\gamma=5000$.

Results for the optimal consumption rule reported in the Appendix show that the optimal consumption behavior that is associated with these portfolio rules depends on both the investor's coefficient of relative risk aversion and her elasticity of intertemporal substitution. An investor with zero elasticity of intertemporal substitution consumes the annuity value of wealth each period, so the average consumption-wealth ratio for this investor is just the average expected return on the portfolio. The average portfolio return declines with risk aversion, and so the average consumption-wealth ratio also declines with risk aversion. Investors with higher elasticities of consumption are willing to substitute intertemporally in 
response to incentives. The direction of the substitution depends on the average return on the portfolio in relation to the time discount rate and the risk of the portfolio. Investors with low risk aversion have high average portfolio returns so they substitute by reducing present consumption, while investors with high risk aversion have low average portfolio returns so they substitute by increasing present consumption. The magnitude of these effects is such that all investors with unit elasticity of substitution have the same average consumption-wealth ratio equal to $(1-\delta)$, regardless of their risk aversion and resulting portfolio composition.

The accuracy of our loglinear approximation to the intertemporal budget constraint depends on the standard deviation of the log consumption-wealth ratio. This standard deviation is zero for $\psi=1$ (the case where our approximation holds exactly) and is roughly proportional to $(\psi-1)$. (It would be exactly proportional if the log-linearization parameter $\rho$ were fixed.) For $\psi$ close to zero, the standard deviation is about 3 percent. This suggests that our approximation should be extremely accurate for a term-structure model of the sort we have estimated in 1952-96. Campbell and Hyeng Keun Koo (1997) use numerical methods to solve a model with an exogenous portfolio return that follows an AR(1) process like the endogenous portfolio return in our model; they find that approximation error is very small whenever the standard deviation of the log consumption-wealth ratio is 5 percent or below.

The volatility of consumption growth depends on the volatility of the optimal portfolio 
return, together with the volatility of the log consumption-wealth ratio. We find that optimal consumption is highly volatile unless investors are extremely risk averse. A simple way to understand this result is as follows. The model parameters estimated for 1952-96 imply that the standard deviation of $m_{t+1}$ is 0.19 if we counterfactually set $\sigma_{m}^{2}=0$. This is the standard deviation of marginal utility for an investor who can trade freely in indexed bonds but has no access to equities or nominal bonds. If utility takes the power form, the standard deviation of marginal utility is the standard deviation of consumption growth times the coefficient of relative risk aversion. Thus with power utility we must have either volatile consumption or high risk aversion, just as in the literature on the equity premium puzzle. With recursive utility, consumption can be somewhat smoother if the elasticity of intertemporal substitution is lower than the reciprocal of risk aversion (a point also noted by Campbell 1996), but this effect is empirically quite small. 


\section{Multiple Assets and Portfolio Constraints}

\section{A. Extended solution procedure}

The results in the previous section can easily be generalized to the case where the investor can hold multiple long-term assets: indexed bonds, nominal bonds, and equities. We can assume that the short-term asset is indexed or nominal, or allow both types of short-term asset. For realism, however, and since inflation risk is modest at the short end of the term structure, we now assume that the one-period asset is nominal.

The Appendix shows that even in the presence of nominal assets, the log consumptionwealth ratio still depends only on the state variable $x_{t}$, and not on expected inflation $z_{t}$. Furthermore this ratio is still a linear function of $x_{t}$, and the slope coefficient is still given by $b_{1}=\rho(1-\psi) /(1-\rho \phi)$ as in equation (28). The menu of available assets affects this coefficient only indirectly by affecting the intercept $b_{0}$ of the consumption function, which in turn determines the log-linearization parameter $\rho$.

We write the vector of allocations to long-term assets as $\boldsymbol{\alpha}$. The residual allocation $\left(1-\boldsymbol{\iota}^{\prime} \boldsymbol{\alpha}\right)$, where $\boldsymbol{\iota}$ is a vector of ones, is to the short-term asset. Then we have

$$
\boldsymbol{\alpha}=\frac{1}{\gamma} \boldsymbol{\Sigma}^{-1} \mathbf{a}
$$

where $\boldsymbol{\Sigma}$ is the variance-covariance matrix of excess returns over the short-term asset and

$$
\mathbf{a}=\mathbf{m}+\gamma \mathbf{p}+\frac{1-\gamma}{1-\psi} \mathbf{h}
$$


Here $\mathbf{m}$ is a vector of Jensen's-Inequality-corrected mean excess returns whose $i$ th element is

$$
m_{i}=\mathrm{E}_{t}\left[r_{i, t+1}-\left(r_{1, t+1}^{\$}-\pi_{t+1}\right)\right]+\frac{1}{2} \operatorname{Var}_{t}\left[r_{i, t+1}-\left(r_{1, t+1}^{\$}-\pi_{t+1}\right)\right],
$$

$\mathbf{p}$ is a vector of conditional covariances with the real return on the short-term bond whose $i$ th element is

$$
p_{i}=\operatorname{Cov}_{t}\left[r_{i, t+1}-\left(r_{1, t+1}^{\$}-\pi_{t+1}\right), r_{1, t+1}^{\$}-\pi_{t+1}\right],
$$

and $\mathbf{h}$ is a vector of conditional covariances with the consumption-wealth ratio whose $i$ th element is

$$
\begin{aligned}
h_{i} & =\operatorname{Cov}_{t}\left[r_{i, t+1}-\left(r_{1, t+1}^{\$}-\pi_{t+1}\right), c_{t+1}-w_{t+1}\right] \\
& =\frac{\rho}{1-\rho \phi}(1-\psi) \operatorname{Cov}_{t}\left[r_{i, t+1}-\left(r_{1, t+1}^{\$}-\pi_{t+1}\right), x_{t+1}\right] .
\end{aligned}
$$

The vector $\mathbf{m}$ gives the standard one-period mean-variance analysis, while the vector $\mathbf{p}$ appears because we have assumed that the short-term asset is nominal so that it is risky in real terms. In practice the elements of $\mathbf{p}$ are all extremely small and have little impact on the portfolio allocation. The vector $\mathbf{h}$ represents the intertemporal hedging component of demand.

The solution of the model is analytical given the loglinearization parameter $\rho$. We find $\rho$ using the same recursive procedure as before; we assume a value for $\rho$, solve the model, get a new value for $\rho$, and so on until convergence.

We can also allow for borrowing and short-sales constraints. Unconstrained portfolio 
allocations are often highly leveraged; but this permits the possibility of bankruptcy in a discrete-time model, and many investors are constrained in their use of leverage. Because the unconstrained optimal portfolio policy is constant over time, we can impose constraints using results in Lucie Teplá (1999). Following J. Cvitanić and I. Karatzas (1993), Teplá (1999) shows that standard results in static portfolio choice with borrowing and short-sales constraints extend to intertemporal models whose unconstrained optimal portfolio policies are constant over time. The optimal portfolio allocations under borrowing constraints are the unconstrained allocations with a higher short-term interest rate, and the optimal portfolio allocations under short-sales constraints are found by reducing the dimensionality of the asset space until the optimal unconstrained allocations imply no short sales. These and all other results given in this section are explained in detail in the Appendix.

\section{B. The demand for nominal bonds}

The third column in Table 3 reports the optimal unconstrained portfolio rules implied by the nominal term structure model estimated over the period 1952-96, assuming that the only assets available to investors are one-quarter and ten-year nominal zero-coupon bonds. Nominal bonds have slightly higher average returns than indexed bonds, but are subject to inflation risk. Table 3 shows that when investors are forced to bear this risk they shorten the maturities of their bond portfolios.

The fourth and fifth columns in Table 3 report solutions when both indexed and nominal 
bonds are available. We allow investors to hold three-month nominal, ten-year nominal, and ten-year indexed bonds. Investors with low risk aversion hold a mix of both indexed and nominal bonds, seeking to earn both the real term premium and the inflation risk premium, and exploiting the imperfect correlations between the real and nominal sources of risk. More conservative investors concentrate their portfolios on indexed bonds.

The last two columns in Table 3 report solutions when the assets available to investors are three-month, three-year, and ten-year nominal bonds. Investors hold highly leveraged portfolios, with long positions in the three-year nominal bond and short positions in the ten-year nominal bond. Risk-tolerant investors do this because they are attracted by the high Sharpe ratio of the three-year nominal bond relative to the Sharpe ratio of the ten-year nominal bond, and they short ten-year bonds to reduce their portfolio risk. Conservative investors exploit the fact that three-year bonds have a greater real-interest-rate sensitivity than ten-year bonds. By shorting ten-year bonds they can hedge the expected-inflation exposure of three-year bonds and create bond portfolios with similar properties to long-term indexed bonds, even though indexed bonds are not directly available in the marketplace. This strategy relies on the ability to sell bonds short and is ruled out if we impose shortsales constraints.

We can use our solutions to consider the partial-equilibrium effects on investors' utility of switching from a world where only nominal bonds are available to a world where all debt instruments are indexed, or to a world where both nominal and indexed bonds are 
available. The analysis is partial-equilibrium in that we hold constant the empirical model for interest rates even as we vary the menu of available assets. We study this question using equation (17), which gives the value function per unit wealth as a monotonic transformation of the optimal consumption-wealth ratio. We can compute an approximate value function without any need for further approximations just by substituting into this expression our approximate consumption-wealth ratio. ${ }^{11}$ The $\log$ value function is a linear function of the short-term interest rate, so it is time-varying; we calculate its unconditional mean.

Results reported in the Appendix for the 1952-96 sample show that bond indexation can have substantial benefits for conservative investors. At the short end of the term structure, the replacement of a nominal short-term asset with an indexed short-term asset eliminates the risk of unexpected inflation; although this risk is small, it does affect the welfare of extremely conservative investors. More importantly, indexation eliminates the risk in longterm bonds caused by changes in expected future inflation. Investors who can trade freely in both intermediate-term and long-term nominal bonds can hedge this risk, but shortsales-constrained investors cannot. These investors benefit greatly from the introduction of indexed bonds. A constrained investor with $\gamma=10(5)$ and $\psi=1$, for example, gains utility equivalent to a 33 (11) percent increase in wealth from trading three-month nominal, ten-year nominal and ten-year indexed bonds rather than three-month, three-year, and ten-year nominal bonds, and gains almost as much by trading only three-month and ten-year indexed bonds. Results for the 1983-96 sample are qualitatively similar but imply 
considerably smaller benefits of bond indexation. The Volcker-Greenspan monetary regime has greatly reduced long-run uncertainty about inflation, and has correspondingly reduced the benefits of eliminating inflation risk entirely.

These findings contradict the claim of Viard (1993) that indexation has only minor effects on investors' utility. Viard models indexation as elimination of the inflation risk in a oneperiod asset, and studies the benefits to one-period investors. Since there is little risk in inflation over one period, Viard's result is not surprising. We get much larger benefits of indexation because we model indexation as elimination of the inflation risk in long-term assets, and study the benefits to long-term investors. ${ }^{12}$

Advocates of bond indexation have sometimes argued that the availability of indexed assets will stimulate saving. However this effect depends on the elasticity of intertemporal substitution, $\psi$. If $\psi=1$, then the consumption-wealth ratio is constant regardless of the available asset menu. If $\psi$ is close to zero, as many empirical estimates suggest, then the consumption-wealth ratio approximately equals the value function. Thus the utility gain from indexation is accompanied by an increase in consumption and a decline in saving.

All these calculations depend on the assumption that the process driving interest rates is invariant to the presence or absence of inflation-indexed bonds. This assumption might be defensible in a small open economy, but is unlikely to hold in the general equilibrium of a closed economy. Thus our results are not a reliable guide to the effects of bond indexation on social welfare. They do, however, make it hard to argue the irrelevance of indexation. If 
bond indexation does not change the stochastic process driving interest rates, it must have utility benefits for constrained conservative investors; if it does not help such investors, it must have effects on interest rates.

\section{Bond Demand in the Presence of Equities}

The realism of the preceding analysis is limited by the fact that we have not allowed investors to hold equities. We now consider a scenario in which both bonds and equities are available to the investor.

Table 4 reports optimal demands for equities and for 3-month and 10-year indexed or nominal bonds by investors who are unconstrained or subject to borrowing and short-sales constraints. For simplicity we assume either that short- and long-term bonds are all indexed, or that they are all nominal; we do not allow investors to hold equities, indexed bonds, and nominal bonds simultaneously. Panel A reports results for the 1952-96 sample, which we consider first.

In a world with full indexation, the unconstrained demand for both long-term indexed bonds and equities is positive and often above 100 percent, implying that the investor optimally borrows to finance purchases of equities and indexed bonds. The portfolio share of indexed bonds exceeds that of equities, despite the higher Sharpe ratio of equities, because indexed bonds are much less risky than equities. ${ }^{13}$ As the coefficient of relative risk aversion increases, the demands for both long-term indexed bonds and equities fall, but the share of 
equities falls faster. In the limit the infinitely risk-averse investor holds a portfolio equivalent to an indexed perpetuity as we have already discussed. When there are borrowing and short-sale constraints, investors with low risk aversion invest fully in equities as a way to maximize their risk and expected return without using leverage, while more risk-averse investors hold both indexed bonds and equities. Cash plays only a minor role and only in the portfolios of the most risk-averse investors, who are almost fully invested in indexed bonds.

These findings are related to the "asset allocation puzzle" of Canner et al. (1997). Investment advisers often suggest that more conservative investors should have a higher ratio of long-term bonds to stocks in their portfolios. Canner et al. document this feature of conventional investment advice and point out that it is inconsistent with the mutual fund theorem of static portfolio analysis, according to which risk aversion should affect only the ratio of cash to risky assets and not the relative weights on different risky assets.

Our analysis shows that static portfolio analysis can be seriously misleading when investment opportunities are time-varying and investors have long time horizons. The portfolio allocations to equities and indexed bonds in Panel A of Table 4 are strikingly consistent with conventional investment advice. Aggressive long-term investors should hold stocks, while conservative ones should hold long-term bonds and small amounts of cash. The explanation is that long-term bonds, and not cash, are the riskless asset for long-term investors. ${ }^{14}$

A weakness in this resolution of the asset allocation puzzle is that it assumes that longterm bonds are indexed, or equivalently, that there is no inflation uncertainty. Panel A of 
Table 4 shows that nominal bonds play a much smaller role in optimal portfolios. In a world with no indexation, unconstrained investors with low risk aversion hold modest nominal bond positions, but constrained investors hold only equities. As risk aversion increases, investors move into cash rather than long-term nominal bonds. Figure 1 illustrates this point. The top panel of the figure plots constrained allocations to equities, a ten-year nominal bond and a three-month nominal bill, while the bottom panel plots constrained myopic allocations. The horizontal axis measures relative risk tolerance $(1 / \gamma)$ rather than relative risk aversion, because both total and myopic allocations are linear in risk tolerance when portfolio constraints are not binding. Infinitely conservative investors with $1 / \gamma=0$ are plotted at the right edge of the figure. As in the tables we set $\psi=1$, but the choice of $\psi$ has very little effect on the results.

Risk-tolerant investors at the left of Figure 1 are fully invested in equities. Highly riskaverse investors hold most of their portfolios in cash, although they also hold some ten-year nominal bonds. The bottom panel shows that long-term bonds are held purely for hedging purposes. The myopic demand for long-term bonds is extremely close to zero at all levels of risk aversion.

The portfolio allocations to nominal bonds in Panel A of Table 4 and Figure 1 do not correspond well with conventional investment advice. In order to rationalize the conventional wisdom about long-term nominal bonds, one must assume that future interest rates will be generated by a different process than the one estimated in 1952-96, a process with less 
uncertainty about future inflation. ${ }^{15}$ Interestingly, we have estimated just such a process over the Volcker-Greenspan sample period 1983-96. Panel B of Table 4 repeats Panel A using our 1983-96 estimates and finds that even when only nominal bonds are available, aggressive long-term investors should hold stocks, while conservative ones should hold primarily longterm nominal bonds along with small quantities of stocks. ${ }^{16}$

Figure 2, whose structure is identical to Figure 1, emphasizes this result. Panel A shows that almost all investors should be fully invested in equities and long-term nominal bonds when they face a term structure like the one estimated for the Volcker-Greenspan era. Only extremely risk-averse investors should hold some cash in their portfolios. Panel B shows that intertemporal hedging motives account for most of this demand for long-term nominal bonds. If investors behaved myopically and ignored the hedging properties of long-term bonds, their portfolios would contain mostly equities and cash. The top panel of Figure 2 also shows that the ratio of nominal bonds to equities in the optimal portfolio increases with risk aversion, just as recommended by conventional investment advice. If investors behaved myopically, this ratio would be constant when portfolio constraints are not binding, as shown in the bottom panel.

Although our 1983-96 model replicates important features of conventional investment advice, it still falls short in one respect. The optimal portfolios in Figure 2 contain very little cash relative to the recommended portfolios reported by Canner, Mankiw, and Weil (1997). We do not attempt to match those portfolios more accurately, but suspect that it 
can be done either by using a term-structure process intermediate between the two processes we have estimated, or by modelling liquidity motives for holding cash.

Finally, we note that our resolution of the asset allocation puzzle does not escape the equity premium puzzle. That is, unconstrained investors in our model have highly volatile marginal utility, implying either high risk aversion or volatile consumption growth. Even in the presence of portfolio constraints, a risk-tolerant investor who holds a 100 percent equity portfolio will have consumption volatility similar to the volatility of stock returns and much higher than the volatility of aggregate consumption growth. To reconcile our results with aggregate consumption data, one would need to assume either that most investors are highly risk-averse, or that many consumers face tighter portfolio constraints than those modelled here, with low risk exposure that reduces the volatility of aggregate consumption. 


\section{Conclusion}

In this paper we have considered infinite-lived investors who use their wealth to finance a stream of consumption. We have shown that such investors may hold long-term bonds for two reasons. First, if long-term bonds offer a term premium then investors may hold them for speculative purposes, to increase their expected portfolio return even at the cost of some extra short-term risk. This "myopic demand" for long-term bonds can be large when risk aversion is small, because long-term bonds have attractive Sharpe ratios. Second, long-term investors may hold long-term bonds for hedging purposes. Long-term bonds can finance a stable long-run consumption stream even in the face of time-varying short-term interest rates, and this is attractive to risk-averse long-term investors. In the extreme cases where there is no term premium, or where investors are infinitely risk-averse, the myopic demand for long-term bonds is zero and all bond demand is accounted for by the hedging demand.

Inflation-indexed bonds are particularly suitable for hedging purposes, because they do not impose extraneous inflation risk on long-term investors seeking a stable real consumption path. When long-term indexed bonds are available, an infinitely risk-averse long-term investor with zero intertemporal elasticity of substitution holds a bond portfolio that is equivalent to an indexed perpetuity. There is a sense in which the indexed perpetuity is the riskless asset for a long-term investor, since it finances a constant consumption stream forever. When only nominal bonds are available, highly risk-averse investors shorten their bond portfolios in order to reduce their exposure to inflation risk. Less risk-averse investors 
hold long-term nominal bonds for speculative purposes if there is a positive inflation risk premium.

We have extended our approach to solve the intertemporal portfolio choice problem imposing short-sale and borrowing constraints. This is possible because our solution takes the same form as the solution to a static portfolio choice problem for which standard meanvariance analysis is appropriate. Therefore we can solve our constrained problem using methods that have been developed to solve static problems with portfolio constraints.

Our constrained solution enables us to study the utility effects of bond indexation in a partial-equilibrium framework with a given process for interest rates. When portfolio constraints are in place, and both nominal and indexed bonds are available to investors, conservative investors benefit substantially from the consumption insurance provided by long-term indexed bonds. This should not be interpreted as a social welfare analysis, however, as we hold interest-rate behavior fixed and do not consider possible general-equilibrium effects of bond indexation on real and nominal interest rates.

We have also studied the demand for bonds when equities are available as an alternative investment. We find that the ratio of bonds to stocks in the optimal portfolio increases with risk aversion, very much in line with popular investment advice but contrary to the mutual fund theorem of static portfolio analysis. However the demand for long-term bonds is only large when these bonds are indexed, or when inflation uncertainty is low as it has been in the Volcker-Greenspan monetary policy regime since 1983. 
In this paper we have taken asset-return processes as given and have not asked how asset returns are determined in general equilibrium. The return parameters we have estimated from financial data display the well-known equity premium puzzle. That is, the high estimated rewards for bearing risk in bond and stock markets imply that investors' marginal utilities must be very volatile. This is particularly true if investors are able to hold leveraged portfolios, but is even true in the presence of borrowing and short-sales constraints. Volatile marginal utilities are hard to reconcile with the smoothness of aggregate consumption.

One response to the equity premium puzzle is to argue that historical estimates of risk premia on bonds and stocks are biased upwards by survivorship bias or peso problems. We could of course calculate portfolio solutions with lower risk premia; the myopic components of bond and equity demand would be smaller, but the intertemporal hedging components would be similar to those reported here since they depend on the dynamics of interest rates rather than the levels of risk premia.

A limitation of our work is that we do not consider labor income. It would be straightforward to allow for riskless labor income, or income perfectly correlated with asset returns. As Bodie et al. (1991) have pointed out, such labor income is equivalent to an implicit holding of financial assets; the results of our paper then apply to total asset holdings rather than explicit holdings. In our model with time-varying real interest rates, it is worth noting that riskless real labor income is an implicit holding of a long-term inflation-indexed bond, not an implicit holding of short-term bills. Also, short-sales and borrowing constraints apply to 
explicit holdings of financial assets rather than total holdings, so the presence of labor income would alter the impact of portfolio constraints on our solutions. Portfolio-constrained investors with riskless labor income, for example, would have large implicit inflation-indexed bond holdings and would not be able to reduce these holdings through explicit short-selling of inflation-indexed bonds. Such investors would have smooth consumption and constrained equity holdings; this might help to explain the equity premium puzzle as suggested by Constantinides et al. (1998).

Our approach can be extended in several ways. We can explore alternative term-structure models, adding factors or allowing for changing interest-rate volatility. A particularly tractable possibility is a discrete-time version of the Cox et al. (1985) model, in which interest-rate volatility rises with the level of the interest rate. Since term premia and bond return variances move in proportion to one another, this model delivers constant portfolio allocations.

We can consider the effect of investors' horizons more explicitly by solving a finitehorizon version of our model - an approach taken by Wachter (1998) - or by varying the time discount factor $\delta$. In a model with a constant probability of death each period, an investor with a high death probability has a low $\delta$. Our model predicts that this investor has a high optimal consumption-wealth ratio, a low value for the log-linearization parameter $\rho$, and an optimal portfolio that is close to the optimal portfolio for a myopic single-period investor. 
We can allow for multiple consumption goods, and consider assets that are indexed to the price of one of these goods. A house, for example, can be regarded as an asset that delivers a constant flow of housing services, in the same way that an indexed bond delivers a constant flow of consumption. This perspective might explain why conservative investors are willing to own houses despite the short-run variability of house prices (Marjorie Flavin and Takashi Yamashita 1998).

Our analysis also has interesting implications for the design of pension plans and annuities. Our results suggest that conservative investors will favor indexed defined-benefit plans, while more risk-tolerant investors should be willing to accept some inflation or equity risk in their retirement income in exchange for higher average payments.

Our ultimate goal is to build a more fully realistic model of portfolio choice by combining several of the effects emphasized in the recent literature. This paper explores the impact of interest-rate risk on long-term portfolio choice, while Campbell and Viceira (1999) studies time-variation in the equity premium, and Viceira (1999) considers uninsurable risk in labor income. A complete model accounting for all these effects offers the exciting prospect that financial economists will at last be able to offer realistic but scientifically grounded investment advice. 


\section{References}

Backus, David. "Cox-Ingersoll-Ross in Discrete Time", Unpublished paper, New York University, 1993.

Balduzzi, Perluigi and Lynch, Anthony. "Transaction Costs and Predictability: Some Utility Cost Calculations", Journal of Financial Economics, 1999, 52, pp. 47-78.

Barberis, Nicholas C. "Investing for the Long Run When Returns Are Predictable", forthcoming Journal of Finance, 1999.

Berardi, Andrea. "Term Structure, Non-Neutral Inflation, and Economic Growth: A ThreeFactor Model", Unpublished paper, London Business School, 1997.

Bergstrom, A.R. "Continuous Time Stochastic Models and Issues of Aggregation over Time", Chapter 20 in Zvi Griliches and Michael D. Intriligator, eds., Handbook of Econometrics, Vol. 2. Amsterdan: North-Holland, 1984.

Bodie, Zvi, Kane, Alex, and McDonald, Robert. "Inflation and the Role of Bonds in Investor Portfolios", in Benjamin M. Friedman, ed., Corporate Capital Structures in the United States. Chicago, IL: University of Chicago Press, 1985.

Bodie, Zvi, Merton, Robert C., and Samuelson, William F. "Labor Supply Flexibility and Portfolio Choice in a Life Cycle Model", Journal of Economic Dynamics and Control, 1991, 16, pp. 427-449. 
Brandt, Michael. "Estimating Portfolio and Consumption Choice: A Conditional Euler Equations Approach", forthcoming Journal of Finance, 1999.

Brennan, Michael J., Schwartz, Eduardo S., and Lagnado, Ronald. "The Use of Treasury Bill Futures in Strategic Asset Allocation Programs", Finance Working Paper 7-96, Anderson Graduate School of Management, UCLA, 1996.

-_-_-_ "Strategic Asset Allocation", Journal of Economic Dynamics and Control, 1997, 21, pp. 1377-1403.

Brennan, Michael J. and Xia, Yihong. "Resolution of a Financial Puzzle", Unpublished paper, Anderson Graduate School of Management, UCLA, 1998.

Campbell, John Y. "Intertemporal Asset Pricing without Consumption Data", American Economic Review, 1993, 83, pp. 487-512.

- - - . "Asset Prices, Consumption, and the Business Cycle", forthcoming in John Taylor and Michael Woodford, eds., Handbook of Macroeconomics. Amsterdan: NorthHolland, 1999.

Campbell, John Y. and Koo, Hyeng Keun. "A Comparison of Numerical and Analytical Approximate Solutions to an Intertemporal Consumption Choice Problem", Journal of Economic Dynamics and Control, 1997, 21, pp. 273-295.

Campbell, John Y. and Kyle, Albert S. "Smart Money, Noise Trading, and Stock Price Behavior", Review of Economic Studies, 1993, 60, pp. 1-34. 
Campbell, John Y., Lo, Andrew W., and MacKinlay, A. Craig. The Econometrics of Financial Markets. Princeton, NJ: Princeton University Press, 1997.

Campbell, John Y. and Shiller, Robert J. "A Scorecard for Indexed Government Debt", in Ben S. Bernanke and Julio Rotemberg, eds., NBER Macroeconomics Annual 1996. Cambridge, MA: MIT Press, 1996.

Campbell, John Y. and Viceira, Luis M. "Consumption and Portfolio Decisions when Expected Returns are Time Varying", Quarterly Journal of Economics, 1999, 114, pp. 433-495.

Canner, Niko, Mankiw, N. Gregory, and Weil, David N. "An Asset Allocation Puzzle", National Bureau of Economic Research (Cambridge, MA) Working Paper No. 4857, 1994.

_-_-_-_ "An Asset Allocation Puzzle", American Economic Review, 1997, 87, pp. $181-191$.

Chacko, George and Viceira, Luis M. "Approximation Methods for Continuous-Time Consumption and Investment Problems", Unpublished paper, Graduate School of Business Administration, Harvard University, 1999.

Clarida, Richard, Gali, Jordi, and Gertler, Mark. "Monetary Policy Rules and Macroeconomic Stability: Evidence and Some Theory", National Bureau of Economic Research (Cambridge, MA) Working Paper No. 6442, 1998. 
Cocco, Joao, Gomes, Francisco, and Maenhout, Pascal. "Consumption and Portfolio Choice over the Life Cycle", Unpublished paper, Harvard University, 1998.

Cochrane, John H. and Hansen, Lars P. "Asset Pricing Explorations for Macroeconomics", in Olivier J. Blanchard and Stanley Fischer, eds., NBER Macroeconomics Annual 1992. Cambridge, MA: MIT Press, 1992.

Constantinides, George M., Donaldson, John B., and Mehra, Rajnish. "Junior Can't Borrow: A New Perspective on the Equity Premium Puzzle", National Bureau of Economic Research (Cambridge, MA), Working Paper No. 6617, 1998.

Cox, John C. and Huang, Chi-fu. "Optimal Consumption and Portfolio Policies when Asset Prices Follow a Diffusion Process", Journal of Economic Theory, 1989, 39, pp. 33-83.

Cox, John C., Ingersoll, Jonathan E. Jr., and Ross, Stephen A. "A Theory of the Term Structure of Interest Rates", Econometrica, 1985, 53, pp. 385-407.

Cvitanić, J. and Karatzas, I. "Convex Duality in Constrained Portfolio Optimization", Annals of Applied Probability, 1992, 2, pp. 767-818.

Dai, Qiang and Singleton, Kenneth J. "Specification Analysis of Affine Term Structure Models", forthcoming Journal of Finance, 1999.

Duffie, Darrell and Kan, Rui. "A Yield-Factor Model of Interest Rates", Mathematical Finance, 1996, pp. 379-406. 
Epstein, Lawrence and Zin, Stanley. "Substitution, Risk Aversion, and the Temporal Behavior of Consumption and Asset Returns: A Theoretical Framework", Econometrica, 1989, 57, pp. 937-69.

. "Substitution, Risk Aversion, and the Temporal Behavior of Consumption and Asset Returns: An Empirical Investigation", Journal of Political Economy, 1991, 99, pp. 263-286.

Fischer, Stanley. "The Demand for Index Bonds", Journal of Political Economy, 1975, 83, pp. 509-534.

Flavin, Marjorie and Yamashita, Takashi. "Owner-Occupied Housing and the Composition of the Household Portfolio", National Bureau of Economic Research (Cambridge, MA) Working Paper No. 6389, 1998,

Foresi, Silverio, Penati, Alessandro, and Pennacchi, George. "Indexed Bonds and the Inflation Risk Premium", Unpublished paper, University of Illinois, 1997.

Gibbons, Michael R. and Ramaswamy, Krishna. "A Test of the Cox, Ingersoll, and Ross Model of the Term Structure", Review of Financial Studies, 1993, 6, pp. 619-658.

Giovannini, Alberto and Weil, Philippe. "Risk Aversion and Intertemporal Substitution in the Capital Asset Pricing Model", National Bureau of Economic Research (Cambridge, MA) Working Paper No. 2824, 1989. 
Gong, Frank F. and Remolona, Eli M. "Inflation Risk in the US Yield Curve: The Usefulness of Indexed Bonds", Unpublished paper, Federal Reserve Bank of New York, 1996a.

. "A Three-Factor Econometric Model of the US Term Structure", Unpublished paper, Federal Reserve Bank of New York, 1996b.

Hansen, Lars P. and Jagannathan, Ravi. "Restrictions on Intertemporal Marginal Rates of Substitution Implied by Asset Returns", Journal of Political Economy, 1991, 99, pp. $225-262$.

Harvey, Andrew C. Forecasting, Structural Time Series, and the Kalman Filter. Cambridge, UK: Cambridge University Press, 1989.

Heaton, John and Lucas, Deborah J. "Evaluating the Effects of Incomplete Markets on Risk Sharing and Asset Pricing", Journal of Political Economy, 1996, 104, pp. 443487.

Hicks, John. Value and Capital, 2nd ed. Oxford, UK: Oxford University Press, 1946.

Keynes, John M. A Treatise on Money, Vol. II. London, UK: Harcourt, Brace, and Co., 1930.

Kim, Tong Suk and Omberg, Edward. "Dynamic Nonmyopic Portfolio Behavior", Review of Financial Studies, 1996, 9, pp. 141-161. 
Langetieg, Terence. "A Multivariate Model of the Term Structure", Journal of Finance, 1980, 35, pp. 71-97.

Liu, Jun. "Portfolio Choice in Stochastic Environments", Unpublished paper, Stanford University, 1998.

Lutz, Frederick. "The Structure of Interest Rates", Quarterly Journal of Economics, 1940, 55, pp. 36-63.

McCulloch, J. Huston and Kwon, Heon-Chul. "U.S. Term Structure Data 1947-1991", Working Paper 93-6, Ohio State University, 1993.

Mehra, Rajnish and Prescott, Edward. "The Equity Premium: A Puzzle", Journal of Monetary Economics, 1985, 15, pp. 145-161.

Merton, Robert C. "Lifetime Portfolio Selection Under Uncertainty: The Continuous Time Case", Review of Economics and Statistics, 1969, 51, pp. 247-257.

__-_-_ . "Optimum Consumption and Portfolio Rules in a Continuous-Time Model", Journal of Economic Theory, 1971, 3, pp. 373-413.

_-_-_-_ "An Intertemporal Capital Asset Pricing Model", Econometrica, 1973, 41, pp. $867-87$.

. Continuous Time Finance. Cambridge, MA: Basil Blackwell, 1990. 
Modigliani, Franco and Sutch, Richard. "Innovations in Interest Rate Policy", American Economic Review, 1966, 56, pp. 178-197.

Pennacchi, George. "Identifying the Dynamics of Real Interest Rates and Inflation: Evidence Using Survey Data", Review of Financial Studies, 1991, 4, pp. 53-86.

Restoy, Fernando. "Optimal Portfolio Policies Under Time-Dependent Returns", Bank of Spain (Madrid, Spain) Working Paper 9207, 1992.

Samuelson, Paul A. "Lifetime Portfolio Selection by Dynamic Stochastic Programming", Review of Economics and Statistics, 1969, 51, pp. 239-246.

Shiller, Robert J. "The Volatility of Long-Term Interest Rates and Expectations Models of the Term Structure", Journal of Political Economy, 1979, 87, pp. 1190-1219.

_-_-_- "Consumption, Asset Markets, and Macroeconomic Fluctuations", Carnegie Rochester Conference Series on Public Policy, 1982, 17, pp. 203-238.

_-_-_- "The Term Structure of Interest Rates", in Ben Friedman and Frank Hahn, eds., Handbook of Monetary Economics. Amsterdam, The Netherlands: North-Holland, 1990.

Singleton, Kenneth J. "Specification and Estimation of Intertemporal Asset Pricing Models", in Ben Friedman and Frank Hahn, eds., Handbook of Monetary Economics. Amsterdam, The Netherlands: North-Holland, 1990. 
Sun, Tong-sheng. "Real and Nominal Interest Rates: A Discrete-Time Model and Its Continuous-Time Limit", Review of Financial Studies, 1992, 5, pp. 581-611.

Teplá, Lucie. "Optimal Portfolio Policies with Borrowing and Shortsale Constraints", forthcoming Journal of Economics Dynamics and Control, 1999.

Vasicek, Oldrich. "An Equilibrium Characterization of the Term Structure", Journal of Financial Economics, 1977, 5, pp. 177-188.

Viard, Alan D. "The Welfare Gain from the Introduction of Indexed Bonds", Journal of Money, Credit, and Banking, 1993, 25, pp. 612-628.

Viceira, Luis M. "Optimal Portfolio Choice for Long-Horizon Investors with Nontradable Labor Income", National Bureau of Economic Research (Cambridge, MA) Working Paper No. 7409, 1999.

Wachter, Jessica. "Risk Aversion and Allocation to Long-Term Bonds", Unpublished paper, Graduate School of Business Administration, Harvard University, 1998.

Weil, Philippe. "The Equity Premium Puzzle and the Risk-Free Rate Puzzle", Journal of Monetary Economics, 1989, 24, pp. 401-421. 


\section{Footnotes}

* Campbell: Department of Economics, Littauer Center 213, Harvard University, Cambridge MA 02138, USA, and NBER. Tel 617-496-6448, email john_campbell@harvard.edu. Viceira: Harvard Business School, Morgan Hall 367, Boston MA 02163. Tel 617-495-6331, email lviceira@hbs.edu. Campbell acknowledges the financial support of the National Science Foundation and Viceira acknowledges the financial support of the Bank of Spain. We are grateful for helpful comments on earlier drafts by anonymous referees, Andrew Abel, Qiang Dai, Sanjiv Das, Ravi Jagannathan, Stephen Schaefer, Costis Skiadas, and seminar participants at Chicago, Columbia, Duke, FAME, MIT, Northwestern, Wharton, the NBER Summer Institute, the WFA meetings, and the CEPR European Summer Symposium in Financial Markets at Studienzentrum Gerzensee.

${ }^{1}$ They wrote: "Suppose that a person has an $n$ period habitat; that is, he has funds which he will not need for $n$ periods and which, therefore, he intends to keep invested in bonds for $n$ periods. If he invests in $n$ period bonds, he will know exactly the outcome of his investments as measured by the terminal value of his wealth.... If, however, he stays short, his outcome is uncertain.... Thus, if he has risk aversion, he will prefer to stay long" unless compensated by a term premium (pp. 183-184).

${ }^{2}$ John Y. Campbell et al. (1997), Qiang Dai and Kenneth J. Singleton (1999), and Robert J. Shiller (1990) review the recent bond pricing literature. 
${ }^{3}$ Fischer also considers multiple goods whose relative prices may change; this allows him to introduce multiple indexed bonds, but the bonds are distinguished by the prices to which they are indexed, and not by maturity. Fischer recognizes that his assumptions may be problematic, concluding "It is possible that too little uncertainty about the returns from holding nominal bonds and equity over long periods is reflected in the basic model of the paper and that such uncertainty would result in portfolio holders being willing to pay a substantial premium for a long-term indexed bond" (p. 528). This paper explores Fischer's conjecture.

${ }^{4}$ Since circulating the first version of this paper we have become aware of numerical work by Brennan et al. (1996) exploring long-term investors' demand for long-term bonds. More recent analytical work on this topic includes Brennan and Yihong Xia (1998), Jun Liu (1998), and Jessica A. Wachter (1998).

${ }^{5}$ Brennan and Xia (1998), Liu (1998), and Wachter (1998) also use affine yield models but do not distinguish between real and nominal bonds.

${ }^{6}$ To economize space, throughout the article we omit some proofs and empirical results of secondary importance. However, we have included all of them in an Appendix which is readily available from the authors or from their personal web pages: http://www.economics.harvard. edu/faculty/jcampbell/campbell.html and http://www.people.hbs.edu/lviceira.

${ }^{7}$ This result is somewhat sensitive to the sample period. If we estimate the model over the period 1952-79, we find a smaller inflation risk premium at the short end of the term 
structure, consistent with the results of Foresi et al. (1997).

${ }^{8}$ Investors with $\gamma<1$, on the other hand, prefer to hold assets that pay off when investment opportunities are good; they "reverse hedge" the risk of adverse shifts in investment opportunities.

${ }^{9}$ This result does not depend on our use of a loglinear approximate solution method. Brennan and Xia (1998) and Wachter (1998) derive the result without approximation in a continuous-time, finite-horizon model assuming a Vasicek (1977) term structure and power utility defined over terminal wealth and consumption, respectively. Wachter also proves the result in a more general class of models.

${ }^{10}$ In the case of power utility $(\psi \equiv 1 / \gamma)$, the discrete-time equivalent of the Cox-Huang $\mathrm{PDE}$ is given by the expectational difference equation

$$
\frac{W_{t}^{*}}{C_{t}}=\mathrm{E}_{t}\left[\left(1+\frac{W_{t+1}^{*}}{C_{t+1}}\right) \delta^{\frac{1}{\gamma}} M_{t+1}^{1-\frac{1}{\gamma}}\right],
$$

where $W_{t+1}^{*} \equiv W_{t}-C_{t}$ is invested wealth. This equation follows from the Euler equation (15), after substituting in $R_{p, t+1}=\left(W_{t+1}^{*}+C_{t+1}\right) / W_{t}^{*}$ and noting that under complete markets we have $\delta\left(C_{t+1} / C_{t}\right)^{-\gamma}=M_{t+1}$. When loglinearized around the mean log consumption-wealth ratio, this expectational difference equation has the same solution that we have already derived.

${ }^{11}$ For very low $\psi$, the value function per unit wealth actually equals the consumptionwealth ratio. We handle the case $\psi=1$ by taking appropriate limits in (17). Campbell and 
Viceira (1999) provide a more detailed discussion in a related model.

${ }^{12}$ Campbell and Shiller (1996) also emphasize the benefits of indexation to long-term investors, but they do not present a formal analysis.

${ }^{13} \mathrm{~A}$ myopic investor facing independent risks allocates a share to each risk that is proportional to its mean divided by its variance, or equivalently its Sharpe ratio divided by its standard deviation. Although equities have a higher Sharpe ratio than indexed bonds, their standard deviation is much higher so the optimal equity share is lower.

${ }^{14}$ Canner et al. are aware of the potential importance of intertemporal hedging demand for the asset allocation puzzle. They write "In principle, intertemporal hedging of the sort discussed by Merton could point in the right direction.... Unfortunately, the magnitude of this effect is not evident a priori, and the empirical literature on intertemporal hedging lags far behind the theoretical literature" (p. 187). This paper attempts to bridge the gap they identify between empirical and theoretical work on intertemporal hedging.

${ }^{15}$ Canner et al. argue in the NBER Working Paper version of their paper (1994) that money illusion might help to resolve the asset allocation puzzle. However they consider money illusion in the context of short-term mean-variance analysis and do not relate it to intertemporal hedging as we do here.

${ }^{16}$ During the $1983-96$ period the interest-rate sensitivity of a ten-year indexed zero-coupon bond is considerably less than that of an indexed perpetuity. Therefore an infinitely risk- 
averse investor would like to hold a leveraged position in ten-year indexed zeros, which was not the case in our 1952-96 model. To maintain comparability with that model, in Panel B of Table 4 and Figure 2 we replace the ten-year zero-coupon bond with a twenty-year zerocoupon bond. This ensures that the optimal indexed portfolio for an infinitely risk-averse investor is available even when borrowing and short-sales constraints are imposed. 
TABLE 1

Term Structure Model Estimation

\begin{tabular}{|c|c|c|c|c|}
\hline \multirow[b]{2}{*}{ Parameter } & \multicolumn{2}{|c|}{ 1952.I - 1996.III } & \multicolumn{2}{|c|}{ 1983.I - 1996.III } \\
\hline & est. & s.e. & est. & s.e. \\
\hline$\mu_{x}$ & 0.0573 & 0.0298 & 0.0194 & 0.0693 \\
\hline$\mu_{z}$ & 0.0094 & & 0.0087 & \\
\hline$\phi_{x}$ & 0.8688 & 0.0057 & 0.9862 & 0.0042 \\
\hline$\phi_{z}$ & 0.9992 & 0.0012 & 0.8599 & 0.0216 \\
\hline$\beta_{m x}$ & -74.9797 & 41.6949 & -28.6919 & 114.0025 \\
\hline$\beta_{z x}$ & 0.0752 & 0.0516 & -0.4114 & 0.1886 \\
\hline$\beta_{z m}$ & -0.0012 & 0.0006 & 0.0008 & 0.0024 \\
\hline$\beta_{\pi x}$ & 0.5198 & 0.3050 & -0.0267 & 0.9790 \\
\hline$\beta_{\pi m}$ & -0.0088 & 0.0034 & 0.0008 & 0.0193 \\
\hline$\beta_{\pi z}$ & 1.4320 & 0.2940 & -1.5412 & 1.5047 \\
\hline$\beta_{e x}$ & -3.4957 & 3.4123 & -9.3629 & 6.3014 \\
\hline$\beta_{e m}$ & 0.3013 & 0.0979 & 0.5089 & 1.3528 \\
\hline$\sigma_{x}$ & 0.0025 & 0.0001 & 0.0027 & 0.0006 \\
\hline$\sigma_{m}$ & 0.2694 & 0.0927 & 0.1351 & 0.3579 \\
\hline$\sigma_{z}$ & 0.0013 & 0.0001 & 0.0016 & 0.0002 \\
\hline$\sigma_{\pi}$ & 0.0071 & 0.0004 & 0.0072 & 0.0018 \\
\hline log-lik. & \multicolumn{2}{|c|}{26.3327} & \multicolumn{2}{|c|}{26.8222} \\
\hline no. obs. & \multicolumn{2}{|c|}{179} & \multicolumn{2}{|c|}{55} \\
\hline$E\left[r_{1, t+1}\right]$ & \multicolumn{2}{|c|}{$1.39 \%$} & \multicolumn{2}{|c|}{$2.93 \%$} \\
\hline$E\left[r_{1, t+1}^{\$}\right]$ & \multicolumn{2}{|c|}{$5.50 \%$} & \multicolumn{2}{|c|}{$6.40 \%$} \\
\hline$\sigma\left(r_{1, t+1}\right)$ & \multicolumn{2}{|c|}{$1.01 \%$} & \multicolumn{2}{|c|}{$3.25 \%$} \\
\hline$\sigma\left(r_{1, t+1}^{\$}\right)$ & \multicolumn{2}{|c|}{$6.70 \%$} & \multicolumn{2}{|c|}{$3.09 \%$} \\
\hline$E\left[\pi_{t+1}\right]$ & \multicolumn{2}{|c|}{$3.77 \%$} & \multicolumn{2}{|c|}{$3.49 \%$} \\
\hline$\sigma_{t}\left(\pi_{t+1}\right)$ & \multicolumn{2}{|c|}{$1.57 \%$} & \multicolumn{2}{|c|}{$1.52 \%$} \\
\hline
\end{tabular}


TABLE 2

Sample and Implied Moments of the Term Structure

\begin{tabular}{|c|c|c|c|c|c|c|c|c|}
\hline \multicolumn{3}{|c|}{ Moment } & \multicolumn{3}{|c|}{ 1952.I - 1996.III } & \multicolumn{3}{|c|}{ 1983.I - 1996.III } \\
\hline & & & $1 \mathrm{yr}$. & 3 yr. & $10 \mathrm{yr}$. & $1 \mathrm{yr}$. & 3 yr. & $10 \mathrm{yr}$. \\
\hline \multicolumn{9}{|c|}{ A: Nominal Term Structure } \\
\hline (1) & $E\left[r_{n, t+1}^{\$}-r_{1, t+1}^{\$}\right]+\sigma^{2}\left(r_{n, t+1}^{\$}-r_{1, t+1}^{\$}\right) / 2$ & $\begin{array}{l}\text { sample } \\
\text { implied } \\
\text { (s.e.) }\end{array}$ & $\begin{array}{c}0.397 \\
0.559 \\
(0.272)\end{array}$ & $\begin{array}{c}0.651 \\
1.290 \\
(0.655)\end{array}$ & $\begin{array}{c}0.915 \\
1.967 \\
(1.071)\end{array}$ & $\begin{array}{c}0.706 \\
0.155 \\
(0.570)\end{array}$ & $\begin{array}{c}2.111 \\
0.658 \\
(2.373)\end{array}$ & $\begin{array}{c}5.675 \\
2.278 \\
(8.307)\end{array}$ \\
\hline$(2)$ & $\sigma\left(r_{n, t+1}^{\$}-r_{1, t+1}^{\$}\right)$ & $\begin{array}{l}\text { sample } \\
\text { implied } \\
\text { (s.e.) }\end{array}$ & $\begin{array}{l}1.615 \\
1.634 \\
(0.084)\end{array}$ & $\begin{array}{c}4.615 \\
4.501 \\
(0.263)\end{array}$ & $\begin{array}{l}11.365 \\
11.566 \\
(0.707)\end{array}$ & $\begin{array}{c}1.135 \\
1.312 \\
(0.296)\end{array}$ & $\begin{array}{c}4.220 \\
4.627 \\
(1.171)\end{array}$ & $\begin{array}{l}12.612 \\
14.896 \\
(3.664)\end{array}$ \\
\hline (3) & $S R^{\$}=(1) /(2)$ & $\begin{array}{l}\text { sample } \\
\text { implied } \\
\text { (s.e.) }\end{array}$ & $\begin{array}{c}0.246 \\
0.342 \\
(0.172)\end{array}$ & $\begin{array}{c}0.141 \\
0.287 \\
(0.148)\end{array}$ & $\begin{array}{c}0.080 \\
0.170 \\
(0.091)\end{array}$ & $\begin{array}{c}0.622 \\
0.118 \\
(0.450)\end{array}$ & $\begin{array}{c}0.500 \\
0.142 \\
(0.535)\end{array}$ & $\begin{array}{c}0.450 \\
0.153 \\
(0.579)\end{array}$ \\
\hline (4) & $E\left[y_{n, t+1}^{\$}-y_{1, t+1}^{\$}\right]$ & $\begin{array}{l}\text { sample } \\
\text { implied } \\
\text { (s.e.) }\end{array}$ & $\begin{array}{c}0.440 \\
0.294 \\
(0.142)\end{array}$ & $\begin{array}{c}0.802 \\
0.742 \\
(0.392)\end{array}$ & $\begin{array}{l}1.185 \\
1.174 \\
(0.748)\end{array}$ & $\begin{array}{c}0.527 \\
0.071 \\
(0.283)\end{array}$ & $\begin{array}{c}1.267 \\
0.276 \\
(1.148)\end{array}$ & $\begin{array}{c}2.067 \\
0.766 \\
(4.373)\end{array}$ \\
\hline (5) & $\sigma\left(y_{n, t+1}^{\$}-y_{1, t+1}^{\$}\right)$ & $\begin{array}{l}\text { sample } \\
\text { implied } \\
\text { (s.e.) }\end{array}$ & $\begin{array}{c}0.222 \\
0.182 \\
(0.010)\end{array}$ & $\begin{array}{c}0.409 \\
0.488 \\
(0.026)\end{array}$ & $\begin{array}{c}0.613 \\
0.826 \\
(0.048)\end{array}$ & $\begin{array}{c}0.177 \\
0.140 \\
(0.019)\end{array}$ & $\begin{array}{c}0.341 \\
0.380 \\
(0.045)\end{array}$ & $\begin{array}{c}0.545 \\
0.803 \\
(0.123)\end{array}$ \\
\hline \multicolumn{9}{|c|}{ B: Real Term Structure } \\
\hline (6) & $E\left[r_{n, t+1}-r_{1, t+1}\right]+\sigma^{2}\left(r_{n, t+1}-r_{1, t+1}\right) / 2$ & $\begin{array}{l}\text { implied } \\
\text { (s.e.) }\end{array}$ & $\begin{array}{c}0.490 \\
(0.247)\end{array}$ & $\begin{array}{c}1.075 \\
(0.563)\end{array}$ & $\begin{array}{c}1.345 \\
(0.710)\end{array}$ & $\begin{array}{c}0.245 \\
(0.904)\end{array}$ & $\begin{array}{c}0.851 \\
(3.139)\end{array}$ & $\begin{array}{c}2.513 \\
(9.289)\end{array}$ \\
\hline (7) & $\sigma\left(r_{n, t+1}-r_{1, t+1}\right)$ & $\begin{array}{l}\text { implied } \\
\text { (s.e.) }\end{array}$ & $\begin{array}{c}1.309 \\
(0.071)\end{array}$ & $\begin{array}{c}2.994 \\
(0.184)\end{array}$ & $\begin{array}{c}3.788 \\
(0.275)\end{array}$ & $\begin{array}{c}1.590 \\
(0.369)\end{array}$ & $\begin{array}{c}5.521 \\
(1.263)\end{array}$ & $\begin{array}{l}16.295 \\
(3.708)\end{array}$ \\
\hline (8) & $S R=(6) /(7)$ & $\begin{array}{l}\text { implied } \\
\text { (s.e.) }\end{array}$ & $\begin{array}{c}0.374 \\
(0.198)\end{array}$ & $\begin{array}{c}0.374 \\
(0.198)\end{array}$ & $\begin{array}{c}0.374 \\
(0.198)\end{array}$ & $\begin{array}{c}0.154 \\
(0.590)\end{array}$ & $\begin{array}{c}0.154 \\
(0.590)\end{array}$ & $\begin{array}{c}0.154 \\
(0.590)\end{array}$ \\
\hline (9) & $E\left[y_{n, t+1}-y_{1, t+1}\right]$ & $\begin{array}{l}\text { implied } \\
\text { (s.e.) }\end{array}$ & $\begin{array}{c}0.253 \\
(0.130)\end{array}$ & $\begin{array}{c}0.665 \\
(0.347)\end{array}$ & $\begin{array}{c}1.100 \\
(0.581)\end{array}$ & $\begin{array}{c}0.118 \\
(0.455)\end{array}$ & $\begin{array}{c}0.381 \\
(1.620)\end{array}$ & $\begin{array}{c}0.858 \\
(5.177)\end{array}$ \\
\hline$(10)$ & $\sigma\left(y_{n, t+1}-y_{1, t+1}\right)$ & $\begin{array}{l}\text { implied } \\
\text { (s.e.) }\end{array}$ & $\begin{array}{c}0.182 \\
(0.010)\end{array}$ & $\begin{array}{c}0.486 \\
(0.026)\end{array}$ & $\begin{array}{c}0.816 \\
(0.045)\end{array}$ & $\begin{array}{c}0.067 \\
(0.020)\end{array}$ & $\begin{array}{c}0.235 \\
(0.070)\end{array}$ & $\begin{array}{c}0.738 \\
(0.204)\end{array}$ \\
\hline \multicolumn{9}{|c|}{ C: Equities } \\
\hline (11) & $\begin{array}{l}E\left[r_{e, t+1}-\left(r_{1, t+1}^{\$}-\pi_{t+1}\right)\right] \\
+\sigma^{2}\left(r_{e, t+1}-\left(r_{1, t+1}^{\$}-\pi_{t+1}\right)\right) / 2\end{array}$ & $\begin{array}{l}\text { sample } \\
\text { implied } \\
\text { (s.e.) }\end{array}$ & & $\begin{array}{c}6.910 \\
8.988 \\
(3.131)\end{array}$ & & & $\begin{array}{l}8.738 \\
4.527 \\
(9.212)\end{array}$ & \\
\hline$(12)$ & $\sigma\left(r_{e, t+1}-\left(r_{1, t+1}^{\$}-\pi_{t+1}\right)\right)$ & $\begin{array}{l}\text { sample } \\
\text { implied } \\
\text { (s.e.) }\end{array}$ & & $\begin{array}{l}15.917 \\
15.896 \\
(0.708)\end{array}$ & & & $\begin{array}{l}14.646 \\
14.748 \\
(1.069)\end{array}$ & \\
\hline (13) & $S R=(11) /(12)$ & $\begin{array}{l}\text { sample } \\
\text { implied } \\
\text { (s.e.) }\end{array}$ & & $\begin{array}{l}0.434 \\
0.565 \\
(0.184)\end{array}$ & & & $\begin{array}{c}0.597 \\
0.307 \\
(0.621)\end{array}$ & \\
\hline
\end{tabular}


TABLE 3

Optimal Percentage Allocation to n-Period Bond and Percentage Hedging Demand Over Total Demand

\begin{tabular}{|c|c|c|c|c|c|c|}
\hline R.R.A. & $\begin{array}{c}\text { Indexed } \\
\text { Only }\end{array}$ & $\begin{array}{c}\text { Nominal } \\
\text { Only }\end{array}$ & $\begin{array}{c}10-y r \\
\text { Indexed }\end{array}$ & $\begin{array}{c}10-y r \\
\text { Nominal }\end{array}$ & $\begin{array}{c}3 \text {-yr } \\
\text { Nominal }\end{array}$ & $\begin{array}{c}10-y r \\
\text { Nominal }\end{array}$ \\
\hline 0.75 & $\begin{array}{c}1286 \\
(-2)\end{array}$ & $\begin{array}{l}193 \\
(-2)\end{array}$ & $\begin{array}{l}841 \\
(-4)\end{array}$ & $\begin{array}{l}108 \\
(0)\end{array}$ & $\begin{array}{c}2602 \\
(-2)\end{array}$ & $\begin{array}{c}-744 \\
(-3)\end{array}$ \\
\hline 1 & $\begin{array}{l}988 \\
(0)\end{array}$ & $\begin{array}{l}147 \\
(0)\end{array}$ & $\begin{array}{c}654 \\
(0)\end{array}$ & $\begin{array}{l}81 \\
(0)\end{array}$ & $\begin{array}{c}1998 \\
(0)\end{array}$ & $\begin{array}{c}-572 \\
(0)\end{array}$ \\
\hline 2 & $\begin{array}{l}541 \\
(9)\end{array}$ & $\begin{array}{l}78 \\
(6)\end{array}$ & $\begin{array}{l}374 \\
(13)\end{array}$ & $\begin{array}{l}40 \\
(0)\end{array}$ & $\begin{array}{c}1091 \\
(8)\end{array}$ & $\begin{array}{c}-315 \\
(9)\end{array}$ \\
\hline 5 & $\begin{array}{l}272 \\
(27)\end{array}$ & $\begin{array}{c}37 \\
(20)\end{array}$ & $\begin{array}{l}206 \\
(37)\end{array}$ & $\begin{array}{c}16 \\
(-2)\end{array}$ & $\begin{array}{l}547 \\
(27)\end{array}$ & $\begin{array}{c}-160 \\
(29)\end{array}$ \\
\hline 10 & $\begin{array}{l}183 \\
(46)\end{array}$ & $\begin{array}{c}23 \\
(36)\end{array}$ & $\begin{array}{l}150 \\
(57)\end{array}$ & $\begin{array}{c}8 \\
(-5)\end{array}$ & $\begin{array}{l}365 \\
(45)\end{array}$ & $\begin{array}{c}-109 \\
(47)\end{array}$ \\
\hline 5000 & $\begin{array}{c}94 \\
(100)\end{array}$ & $\begin{array}{c}9 \\
(100)\end{array}$ & $\begin{array}{c}95 \\
(100)\end{array}$ & $\begin{array}{c}0 \\
(104)\end{array}$ & $\begin{array}{c}184 \\
(100)\end{array}$ & $\begin{array}{c}-57 \\
(100)\end{array}$ \\
\hline
\end{tabular}

Note: The allocations shown on the table assume $\psi=1$. Hedging demands are shown in parentheses. 
TABLE 4

Optimal Percentage Allocation to Equities and to n-Period Bond

\begin{tabular}{|c|c|c|c|c|c|c|c|c|}
\hline \multirow[b]{2}{*}{ R.R.A. } & \multicolumn{2}{|c|}{ Unconstrained } & \multicolumn{2}{|c|}{ Constrained } & \multicolumn{2}{|c|}{ Unconstrained } & \multicolumn{2}{|c|}{ Constrained } \\
\hline & Equity & Indexed & Equity & Indexed & Equity & Nominal & Equity & Nominal \\
\hline \multicolumn{9}{|c|}{ (A) Sample Period: 1952 - 1996} \\
\hline 0.75 & 443 & 1082 & 100 & 0 & 470 & 25 & 100 & 0 \\
\hline 1 & 332 & 835 & 100 & 0 & 352 & 21 & 100 & 0 \\
\hline 2 & 166 & 464 & 100 & 0 & 175 & 15 & 100 & 0 \\
\hline 5 & 66 & 242 & 60 & 40 & 69 & 12 & 69 & 12 \\
\hline 10 & 33 & 168 & 30 & 70 & 33 & 11 & 33 & 11 \\
\hline 5000 & 0 & 94 & 0 & 94 & -2 & 10 & 0 & 10 \\
\hline \multicolumn{9}{|c|}{ (B) Sample Period: $1983-1996$} \\
\hline 0.75 & 262 & -1 & 100 & 0 & 259 & 1 & 100 & 0 \\
\hline 1 & 196 & 21 & 94 & 6 & 195 & 24 & 96 & 4 \\
\hline 2 & 98 & 54 & 53 & 47 & 99 & 58 & 52 & 48 \\
\hline 5 & 39 & 74 & 28 & 72 & 41 & 78 & 25 & 75 \\
\hline 10 & 20 & 81 & 19 & 81 & 22 & 85 & 16 & 84 \\
\hline 5000 & 0 & 88 & 0 & 88 & 3 & 92 & 3 & 92 \\
\hline
\end{tabular}

Note: The allocations shown on the table assume $\psi=1$. 


\section{Figures}

Figure 1. Portfolio choice based on the 1952-96 sample.

A. Constrained allocation to ten-year and three-month nominal bond and equity.

B. Constrained myopic allocation to ten-year and three-month nominal bond and equity.

Figure 2. Portfolio choice based on the 1983-96 sample.

A. Constrained allocation to twenty-year and three-month nominal bond and equity.

B. Constrained myopic allocation to twenty-year and three-month nominal bond and equity. 

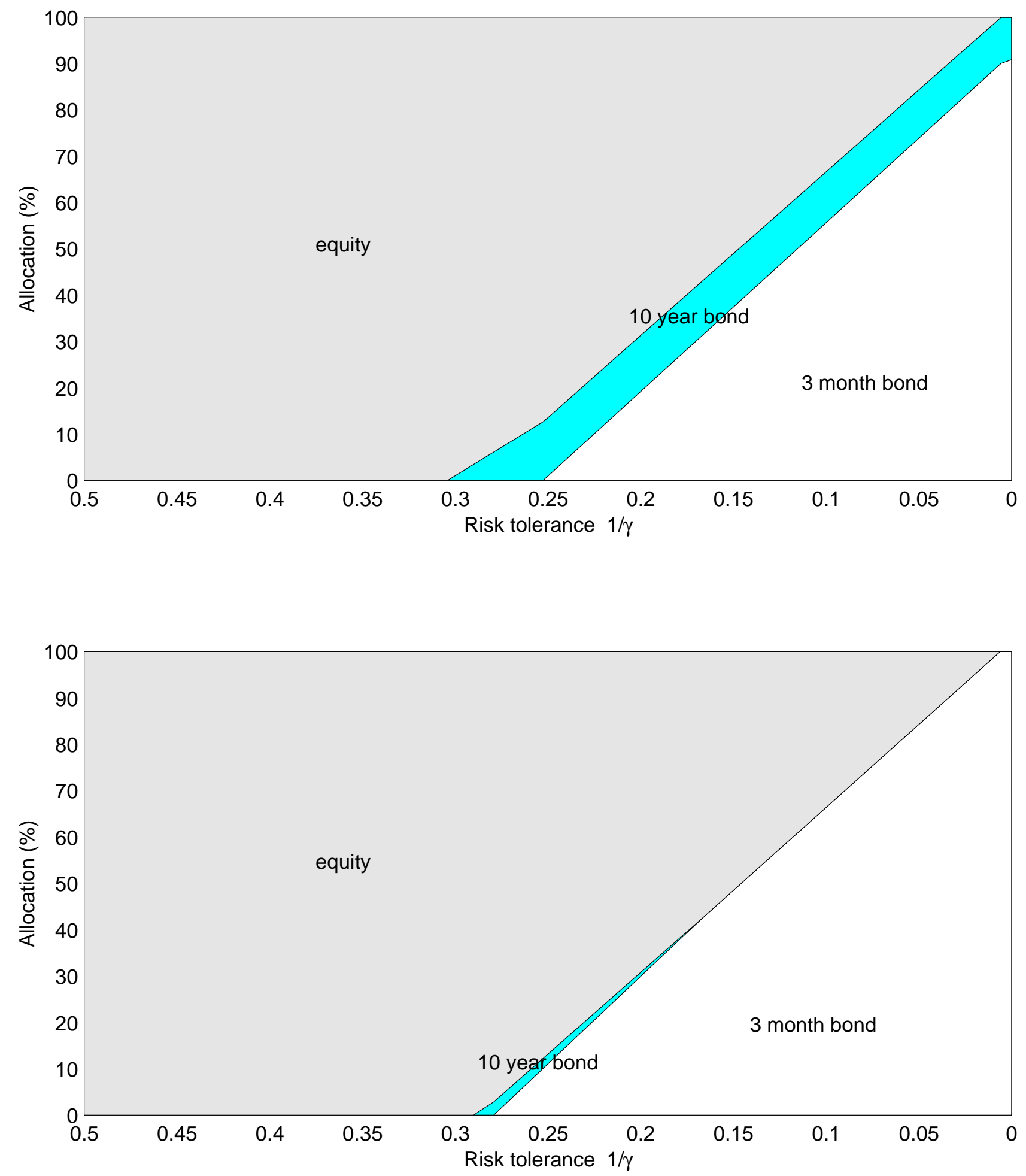

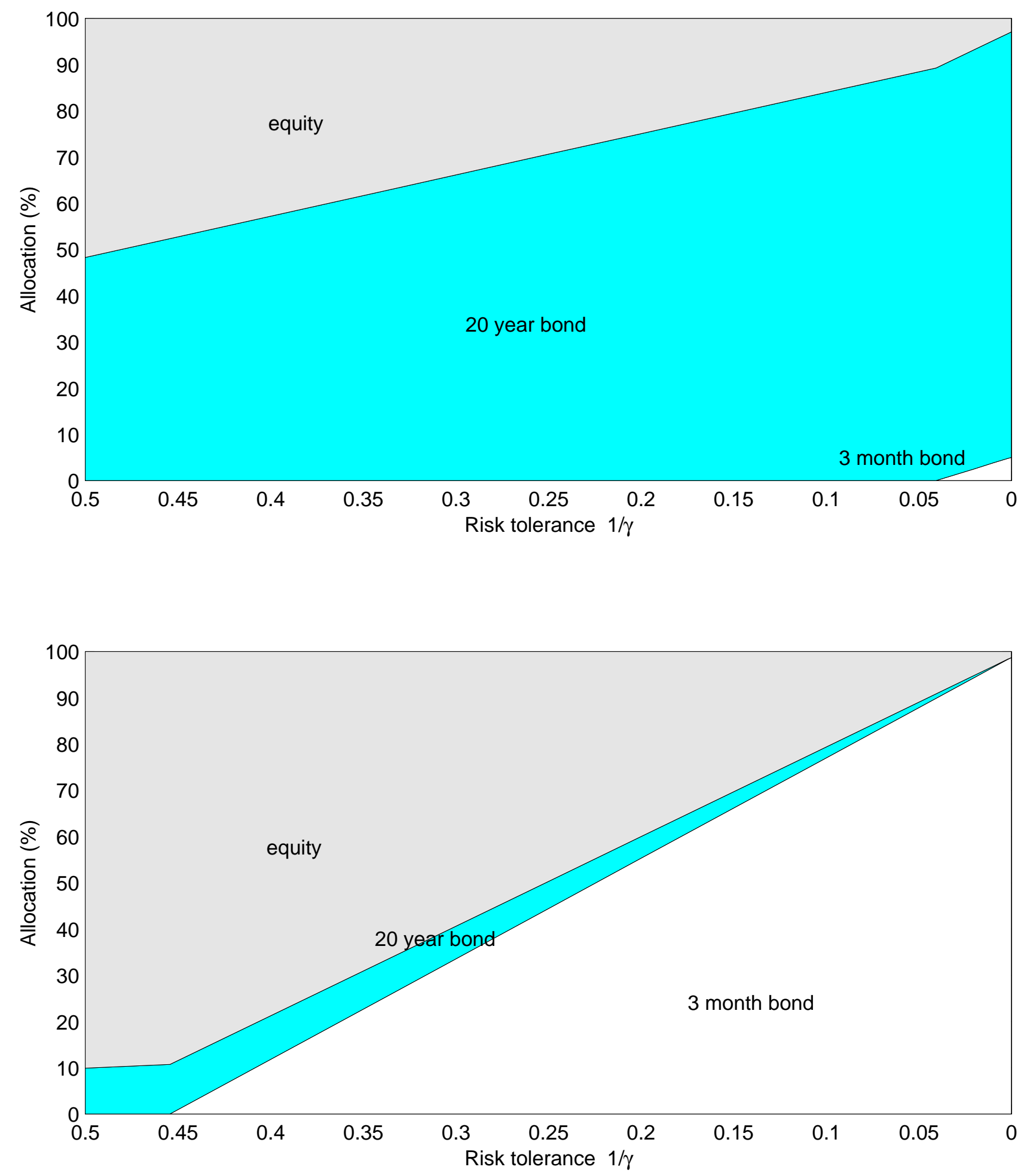